\title{
A Bibliometric Visualization Review of the MODIS LAI/FPAR Products from 1995 to 2020
}

\author{
Kai Yan $\mathbb{D}^{1,2,3}$ Dongxiao Zou $\mathbb{D}^{1},{ }^{1}$ Guangjian Yan $\mathbb{D},{ }^{2}$ Hongliang Fang, ${ }^{4}$ Marie Weiss $\mathbb{D},{ }^{5}$ \\ Miina Rautiainen, ${ }^{6,7}$ Yuri Knyazikhin, ${ }^{3}$ and Ranga B. Myneni ${ }^{3}$ \\ ${ }^{1}$ School of Land Science and Techniques, China University of Geosciences, China \\ ${ }^{2}$ State Key Laboratory of Remote Sensing Science, \\ Jointly Sponsored by Chinese Academy of Sciences and Beijing Normal University, China \\ ${ }^{3}$ Department of Earth and Environment, Boston University, USA \\ ${ }^{4}$ LREIS, Institute of Geographic Sciences and Natural Resources Research, Chinese Academy of Sciences, China \\ ${ }^{5}$ INRAE, Avignon Université, UMR 1114 EMMAH, UMT CAPTE, F-84000 Avignon, France \\ ${ }^{6}$ Department of Built Environment, School of Engineering, Aalto University, Finland \\ ${ }^{7}$ Department of Electronics and Nanoengineering, School of Electrical Engineering, Aalto University, Finland
}

Correspondence should be addressed to Kai Yan; kaiyan@cugb.edu.cn and Dongxiao Zou; dongxiaozou@cugb.edu.cn

Received 26 November 2020; Accepted 3 March 2021; Published 18 March 2021

Copyright (c) 2021 Kai Yan et al. Exclusive Licensee Aerospace Information Research Institute, Chinese Academy of Sciences. Distributed under a Creative Commons Attribution License (CC BY 4.0).

The MODIS LAI/FPAR products have been widely used in various fields since their first public release in 2000. This review intends to summarize the history, development trends, scientific collaborations, disciplines involved, and research hotspots of these products. Its aim is to intrigue researchers and stimulate new research direction. Based on literature data from the Web of Science (WOS) and associated funding information, we conducted a bibliometric visualization review of the MODIS LAI/FPAR products from 1995 to 2020 using bibliometric and social network analysis (SNA) methods. We drew the following conclusions: (1) research based on the MODIS LAI/FPAR shows an upward trend with a multiyear average growth rate of $24.9 \%$ in the number of publications. (2) Researchers from China and the USA are the backbone of this research area, among which the Chinese Academy of Sciences (CAS) is the core research institution. (3) Research based on the MODIS LAI/FPAR covers a wide range of disciplines but mainly focus on environmental science and ecology. (4) Ecology, crop production estimation, algorithm improvement, and validation are the hotspots of these studies. (5) Broadening the research field, improving the algorithms, and overcoming existing difficulties in heterogeneous surface, scale effects, and complex terrains will be the trend of future research. Our work provides a clear view of the development of the MODIS LAI/FPAR products and valuable information for scholars to broaden their research fields.

\section{Introduction}

Leaf area index (LAI) is defined as the one-sided green leaf area per unit ground horizontal area for broadleaf canopies and as the projected needle leaf area for coniferous canopies [1]. The fraction of photosynthetically active radiation (FPAR) is defined as the fraction of incident photosynthetically active radiation (in the range of 400-700 $\mathrm{nm}$ ) absorbed by the green elements of a vegetation canopy under specified illumination conditions [2-5]. Both the LAI and FPAR are expressed as a nondimensional value. LAI gives the number of square meters of leaf material per square meter of ground, and FPAR measures the fraction of the incoming solar radiation at the top of the vegetation canopy that contributes to the photosynthetic activity of plants [6]. LAI and FPAR are key parameters that describe the vegetation canopy structure and its energy absorption capacity [7]. They are of great significance in most ecosystem productivity, climate, hydrological, biogeochemical, and ecological models $[1,8]$, supporting studies on energy or mass (e.g., water and $\mathrm{CO}_{2}$ ) flux dynamics [7]. LAI plays important roles in models describing vegetation-atmosphere interactions, representing processes such as photosynthesis, respiration, and rain interception, that couple vegetation to the climate system through the 
radiation, carbon, and water cycles [6]. FPAR is a primary variable controlling the photosynthetic activity of plants and therefore is an indicator of the intensity of the terrestrial carbon cycle [6], playing a key role in diagnostic terrestrial carbon models known as production efficiency models (PEMs) used to calculate gross and net primary productivity (GPP/NPP) [9-13]. Changes in FPAR have been used as indicators of desertification and to monitor the productivity of agricultural, forest, and natural ecosystems [14]. Both LAI and FPAR have been recognized as two of the essential climate variables for the Global Climate Observing System (GCOS) (https://gcos.wmo.int/en/ essential-climate-variables) of the United Nations [15].

Remote sensing (RS) is incomparable in providing fast and wide-range area observations. With the growing number of earth observation satellites, RS has facilitated a continuous growth of LAI/FPAR-related research [16-18]. The two satellites carrying Moderate Resolution Imaging Spectroradiometers (MODIS) were successfully launched in 1999 and 2002 , respectively. Their advantages of clear theoretical basis, relatively high spatiotemporal resolution, and free access policy contributed to making the MODIS LAI/FPAR products one of the most widely used LAI/FPAR products. MODIS LAI/FPAR are stage 3 standard land data products, which can be obtained free of charge from the Land Processes Distributed Active Archive Center (LP DAAC https://ladsweb .modaps.eosdis.nasa.gov/search/). They have undergone iterative updates from collection 4 (C4) to collection 6 (C6). C6 products have a spatial resolution of $500 \mathrm{~m}$ and a temporal resolution of 4 (MCD) or 8 (MOD and MYD) days. The MODIS official algorithm retrieves LAI/FPAR with a lookup table (LUT) inversion strategy based on the theory of three-dimensional radiative transfer (3D RT) and stochastic radiative transfer (SRT) [19-21]. A detailed description of the MODIS LAI/FPAR algorithm can be found in references $[1,22,23]$. The validity and reliability of the MODIS LAI/FPAR products have been empirically validated $[2,16,20,21$, 24-28]. The root mean square error (RMSE) of the latest version (C6) is 0.66 , which is close to the target accuracy $( \pm 0.5)$ required by the GCOS [27]. There have been numerous relevant studies based on MODIS LAI/FPAR over the past two decades. For instance, Xiao et al. used these products to track canopy recovery rates and trajectory after fire, confirming the value of MODIS LAI/FPAR in fire assessment [29]. Myneni et al. used them to detect large seasonal swings in the leaf area of Amazon rainforests, setting a great example for using MODIS LAI/FPAR to investigate the correlation between LAI/FPAR and changes in regard to climatic, hydrological, and biogeochemical cycles [30]. Mu et al. developed a global evapotranspiration (ET) algorithm using MODIS LAI as a scalar for estimating canopy conductance [31]. Fang et al. used MODIS LAI to estimate corn yield, and the result agreed very well with statistical data, laying the foundation of crop estimation through assimilation of remotely sensed data with a crop growth model [32]. In addition to applying the data to various fields of research, the official MODIS algorithm has also given impetus to many other studies [33-36].

A phase summary is often compiled after a series of research achievements and is accomplished through review papers. Review papers that organize methods, algorithms, products, and applications of a research field or a discipline play an important role in advancing it. In the research field of LAI/FPAR, Weiss et al. reviewed techniques used to derive LAI and leaf inclination angle from gap fraction measurements and discussed sampling strategies based on LAI measurements in various canopies [37]. Fang et al. provided a comprehensive overview of LAI field measurements and remote sensing estimation methods, product validation methods and product uncertainties, and the application of LAI in global studies [38]. Yan et al. comprehensively reviewed the temporal development, theoretical framework, and issues of indirect LAI measurements, followed by current methods, instruments, and platforms [39]. We find that existing review papers related to LAI/FPAR are mainly about the whole research field rather than focused on one specific product, challenging the evaluation of the detailed contribution of individual products. It is also impractical to review the literature manually to quantify research achievements. In recent years, bibliometrics (or scientometrics) has provided a solution for this problem. Bibliometrics is a relatively new statistical technique that has been widely applied to the evaluation of the academic level and research trends of many disciplines [40-47]. It is a quantitative analysis method that integrates mathematics, statistics, and literature studies to calculate statistical summaries and visually analyze the literature [48-50]. This method has been applied to analyzing research fields ranging from a specific topic to the entire discipline [50-53]. Through a literature information analysis and a variety of bibliometric indicators, the overall layout of research hotspots, frontier dynamics, and development trends in a field or a discipline can be quantitatively reflected [48]. Based on objective data and broadly used statistical methods, bibliometrics is less prone to omissions and subjectivity. The bibliometric method allows the visualization of indicators, citation trajectories, and research trends, which can turn massive and confusing information into meaningful and clear knowledge. This method helps readers to quickly obtain the up-to-date status of a field.

On the occasion of the 20th anniversary of the MODIS LAI/FPAR products, we aim to understand how research grants have been related to these products and to quantify the disciplines that benefited from MODIS LAI/FPAR during the past two decades. Discipline interactions can be regarded as interdisciplinary attributes. Connections among disciplines contribute to research ideas or help a research area extend to other research fields. There is currently no bibliometric evaluation of the history and status of the studies that used MODIS LAI/FPAR products. Therefore, this paper sought to fill this gap by developing a bibliometric analysis to summarize the progress of this research area over the past two decades and present an objective history development, applications, and research hotspots of the MODIS LAI/FPAR products. Based on literature from the Web of Science (WOS) core database and funding data from the retrieved literature, with the help of CiteSpace [54] and HistCite [55] software, we drew partnership maps of countries and institutions, a discipline map, a keyword co-occurrence map, and a timeline view of the MODIS LAI/FPAR products. We used 


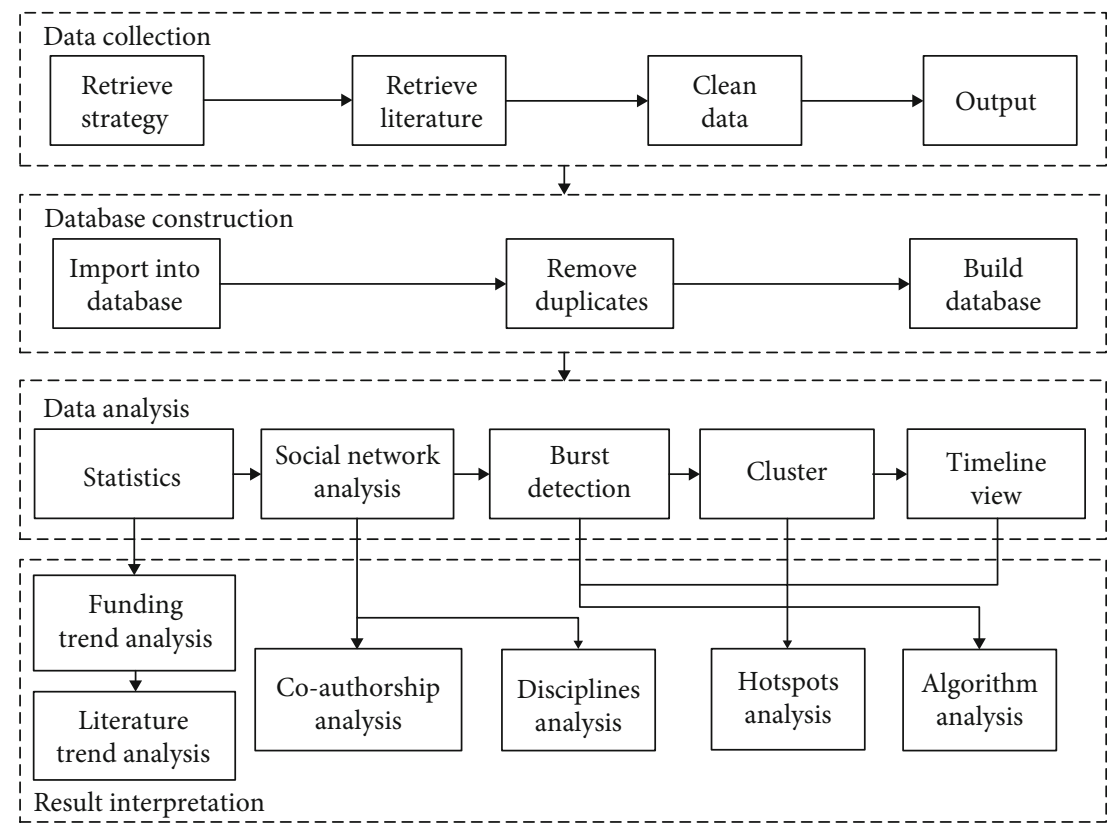

FIGURE 1: Flowchart of the identification of bibliometric elements.

statistical metrics, social network analysis (SNA), burst detection, and cluster analysis. Modularity and Betweenness Centrality Degree (BCD) were used as indicators of SNA, and burst strength was used to measure the burst citation of a publication. Our findings can help the scientific community master the research dynamics, improve the framework of LAI/FPAR research field, and build links among different disciplines.

\section{Materials and Methods}

This study was divided into four parts: data collection, database construction, data analysis, and results interpretation (Figure 1). In the process of data collection, the literature data was retrieved from the WOS core database. The literature data were carefully and manually screened. We imported the "clean data" into HistCite [55] and CiteSpace [54] software to establish a local literature database. In HistCite and CiteSpace, we conducted publication volume analysis, cluster atlas analysis, burst citation analysis, and timeline view analysis. Finally, based on the results obtained in the previous steps, we interpreted the types of publications, discipline involvement, cocitations, and research hotspots.

2.1. Search Strategy and Data Sources. We selected articles and reviews from the core database in WOS. The search formula is "WOS: TS = MODIS LAI OR TS = MODIS "LEAF AREA INDEX" OR TS= MOD15 OR TS = MCD15 OR TS = MYD15 OR TS =MODIS FPAR) AND Languages: (English) AND Types: (Article OR Review)." The search period was between January 1, 1995, and July 15, 2020. A total of 1498 publications were retrieved.

In the literature prereading and retrieval step, we found that many publications only mentioned the MODIS LAI/FPAR data in the introduction or mentioned previous studies that used MODIS LAI/FPAR data instead of the literature itself using the data. Also, there were some publications that used MODIS data for LAI inversion and with no MODIS LAI/FPAR products for comparison. However, this paper only concerns about studies that used MODIS LAI/FPAR datasets or algorithms. Therefore, in order to avoid the impact of data mixing on the analysis results, we carefully cleaned the filtered data by reading the abstracts, data use, and results descriptions.

After elaborated data cleaning, 905 publications were left. Among these publications, 2020's (32 papers) were not used for trend analysis because the records were not complete for the year when we retrieved the data. The dataset containing these 905 publications can be download from https://github .com/DongxiaoZou/Bibliometrics-Data/blob/main/ download_All.txt.

2.2. Bibliometric Methods and Analytical Tools. This paper starts with the trends of funding, basic bibliometric metrics, coauthorship, discipline interactions, hotspots transformation, and algorithm development of the MODIS LAI/FPAR research. The methods and tools used in this paper are as follows.

2.2.1. Funding Information Acquisition. We obtained funding data from the retrieved literature data in the "FU" field. Detail funding data is attached to Table S1 in supplementary materials. By visualizing the annual amount of money and number of funding, we obtained the variations of research period of different countries as a reference.

2.2.2. Basic Bibliometric Metric Analysis. Based on bibliometrics, this paper conducted data analysis on the literature related to the MODIS LAI/FPAR. The analysis of basic metrics was conducted with CiteSpace [54] and HistCite software 
[55]. The basic statistics in this paper included number of publications by year, institute, country, and journal. These descriptive statistics draw an overall picture of the research using MODIS LAI/FPAR or its algorithms.

\subsubsection{Core Research Country/Institution and Collaboration} Mining. To analyze coauthor networks, we conducted a social network analysis (SNA). Known as a type of structural analysis, SNA is a quantitative method that considers the interdependence of individuals. It can intuitively display the overall structure of the network, the position of individuals in the network, and the relationship with other individuals [56]. SNA is widely used in data mining, knowledge management, data visualization, information dissemination, and others [57].

In a network, every node represents a country or an institution; an edge between two nodes represents a coauthorship between the two countries or two institutions. The thicker the edge, the stronger their collaboration relationship, which means that their coauthored publications are more numerous. Here, we used density, modularity $(Q)$, and Betweenness Centrality Degree (BCD) as parameters to describe the elements of a network.

The density of a social network is defined as the actual number of relationships divided by the theoretical maximum number of relationships [58], representing the count of connections among points, which to some degree measures the complexity and completeness of the network. In an undirected network, the density of a network is described as the following Eq. (1) [58].

$$
\text { density }=\frac{2 m}{n(n-1)},
$$

where $m$ represents the actual number of the relationships (i.e., the number of lines), and $n$ represents the nodes in the network. Networks in this paper are all undirected.

In a network with a density of one, every individual has a connection to the others. On the contrary, individuals have no relationship with others in a network with a density of 0 . In conclusion, a network with better density has fewer single points. Research showed that when the density is greater than 0.1 , the network is sufficiently complete to carry enough data size, and the maximum density does not exceed 0.5 in an actual network [59].

Modularity $(Q)$ is a metric that measures the strength of the network community structure, i.e., the degree of clustering among the nodes in the network $[60,61]$. The number of inner lines contained in a cluster positively correlates to the $Q$ value and the clustering effect. The $Q$ can be described as the following Eq. (2) $[42,60]$.

$$
Q=\frac{1}{2 m} \sum_{i j}\left[A_{i j}-\frac{k_{i} k_{j}}{2 m}\right] \delta\left(c_{i}, c_{j}\right) .
$$

In Eq. (2), $m$ represents the edges that exist in the whole network, $k_{i}$ represents the weight of all the connecting edges, and $\delta\left(c_{i}, c_{j}\right)$ is used to tag whether the $i$ th and $j$ th nodes belong to one group, in which 1 stands for true and 0 for false. The $Q$ ranges from 0 to 1 [62], and when it is greater than 0.3 , the cluster structure can be considered significant [60]. This value works the same in the network of disciplines and co-citations.

BCD in a network represents the control index of an individual over other individuals. The BCD is defined as the following Eq. (3) [45].

$$
B C D\left(\text { node }_{i}\right)=\sum_{i \neq j \neq k} \frac{\rho_{j k}(i)}{\rho_{j k}} .
$$

In Eq. (3), $\rho_{j k}$ stands for the number of shortest paths between node $j$ and node $k$, and $\rho_{j k}(i)$ is the number of those paths that pass through node $i$.

One pivotal point with high BCD is highlighted with a purple ring in a visualized network. In the cooperative relationship, $\mathrm{BCD}$ depends on the number of times that the authors jointly complete the same document. The author's country and institution contribute to the BCD of national and institutional cooperation, respectively. It means that $\mathrm{BCD}$ here depends on how many times the authors cooperate. A stronger BCD indicates closer cooperation and connection between the countries and the institutions.

2.2.4. Discipline Network Building. The SNA method provides informative visualizations that can show the connections among disciplines in an area of research. The rules and metrics of SNA mentioned above are also appropriate in this analysis. $\mathrm{BCD}$ of one discipline here measures the connectivity to other disciplines. There are two types of nodes that may have high BCD: (1) hub nodes that are highly connected to other nodes and (2) nodes located between clusters. The latter is more likely to lead to emerging trends than the former, which means that a discipline with high BCD may generate new research directions [41].

Discipline connections can be better visualized through the discipline social network. In this paper, we draw a social network of disciplines with CiteSpace. A social network of disciplines mainly shows the disciplines of all the publications involved, connections between disciplines, and the strengths of the connections. It can indicate future possible research directions of the MODIS LAI/FPAR.

2.2.5. Key Topics and Reference Detection. We used keyword cooccurrence, cocitation timeline view, and burst detection to show the hotspots and their transformation in this research area. The keyword cluster is defined as the group of keywords with a close relationship, while the cocitation cluster is defined as the group of the publications with similar citations (indicating that these publications are likely to share similar research content thus specifying the research domain) [61]. The two kinds of clusters may share common aspects, thus allowing us to infer hotspots. Their transformation can show the track of hotspots. In hotspots detection, high-frequency keywords, high citation literature, and burst literature are paid more attention. 
Cocitation analysis is the most informative part of the bibliometric analysis; it can show highly cited papers in related fields and indicate research progress and migration. Detecting explosive references allows identifying key publications for scholars who want to quickly and comprehensively understand the research progress of the field.

Based on the papers published between January 1995 and July 2020, using one year as the time interval unit, we selected the top 60 citations in every year, constructed the cocitation network of that year, and then synthesized the per-year network into a clustering map. With time on the vertical axis and cluster on the horizontal axis, the documents in each cluster were sorted by publication time to provide a timeline view. Frequency directly indicates the citation counts of one publication. In this case, BCD measures the significance of a publication to other research.

We also used burst detection to monitor the prominent literature. The algorithm for detecting emergence in CiteSpace is Kleinberg's burst monitoring algorithm [63]. The algorithm aims to perform explosive monitoring of data streams by means of text data mining and can extract meaningful structural points from huge datasets, identifying those that have led to high growth of related topics over a period [63]. In this article, this structural point is expressed as an explosive citation in a certain period, which drives a research hotspot and a rapid development of a subfield of literature. The burst strength is used to quantify the impact of the literature in a certain period. In a period of burst time $t_{1}$ to $t_{2}$, the burst strength is defined as Eq. (4) [63].

$$
\text { Burst Strength }=\sum_{t_{1}}^{t_{2}}\left(\sigma\left(0, r_{t}, d_{t}\right)-\sigma\left(1, r_{t}, d_{t}\right)\right) \text {, }
$$

where $r_{t}$ represents the relevant documents out of a total of $d_{t}$ in the $t^{t h}$ batch, and $\sigma\left(i, r_{t}, d_{t}\right)$ stands for a cost of the automaton.

2.2.6. Algorithm Development Trace. To analyze the MODIS LAI/FPAR algorithm trajectory and identify the research output during the algorithm developing process, we conducted cluster analysis and burst detection. The main algorithm of MODIS LAI/FPAR products is based on 3D RT and SRT theories. We selected SRT, 3D RT, and spectral invariants related words as keywords, then filtered the nonrelevant literature by taking the intersection with the search result of vegetation or canopy, retrieving 134 publications. The search was conducted using the formula "WOS: (TS= (( "stochastic radiative transfer" OR SRT OR "3D radiative transfer" OR "three dimension radiative transfer" OR "Photon Recollision Probability" OR "p-theory " OR " $p$ theory" OR "Spectral Invariance" OR "Spectral Invariants" OR "Spectral Invariant") AND (vegetation OR canopy)))AND Languages:(English) AND Types: (Article OR Review)." The search period was between January 1, 1995, and July 15,2020 . After manual examination and removing irrelevant data, 109 publications were left in our dataset. The dataset containing these 109 publications can be download from https:/github.com/DongxiaoZou/Bibliometrics-Data/blob/ main/download_3.6.txt.

\section{Results}

3.1. Funding Analysis. Detailed foundation data is attached to Table S1 in supplementary materials. Generally, we found that the number of funding reported from the literature of China grants greatly exceeded that of other countries (Figure 2). The reason for this phenomenon may be related to the fact that China started relatively late in this research area, and the government paid more and more attention to scientific research in the 21 st century. The peak of China in 2009 may be connected to the releasing of a new collection of the MODIS LAI/FPAR products (C5). The decline in investment after this peak may be caused by the maturity of the instruments, algorithms, and applications. With a slight fluctuation, the funding trend of the US had been generally decreasing. The trends in other countries were not obvious. The investments may have fluctuated with the budget and the research cycle.

\subsection{Basic Bibliometric Analysis}

3.2.1. Country and Institution Distribution. To clarify the publication trend of different countries, we drew Figure 3 with a one-year interval. It can be seen that the publication volume of the MODIS LAI/FPAR in the US, China, and Europe shows an increasing trend, while the publication of other countries shows a fluctuation with a slight increase overall. The total multiyear average growth rate of publication is about $24.9 \%$. The US was the first country to start the research in this field, while China, Europe, and other countries started around 2005 or 2006. China started late, but since 2011, the volume of publications has been surging, and even the growth rate was far higher than that of the US. In 2009, the total number of publications from the US was 121 , while that of China was only 26 . Ten years later, in 2019 , the number of publications of the US was 376 (covering $35 \%$ of the total publications), while that of China was 332 (31\%). In 2015, China peaked with 85 publications, and the US peaked with 72 . Four out of 10 top publishing institutions came from China. They are CAS, BNU, UCAS, and PKU, which rank first, second, fourth, and ninth, respectively. Overall, China accounted for over $60 \%$ of the total publications according to Figure 4.

3.2.2. Journal Distribution. Table 1 shows the top 15 journals publishing the MODIS LAI/FPAR literature, as well as their Total Local Citation Score (TLCS), Total Global Citation Score (TGCS), Impact Factor (IF), and h-index. The TLCS stands for a peer-reviewed situation, while the TGCS reflects the influences of this area on other research areas. "Agricultural and Forest Meteorology" shared almost the same TLCS and TGCS with "Remote Sensing" while its recs was only one-third of that of "Remote Sensing." The "IEEE Transactions on Geoscience and Remote Sensing" ranked fifth and with fewer publications while with higher TLCS and TGCS. The recs of "Journal of Geophysical Research-Atmospheres" was only 25 while its TLCS was as high as 307 , and TGCS was 1474 . The "Remote Sensing" journal had published relatively more papers but with less impact as a new journal [42]. Besides, journals in disciplines like geology, geophysics, 


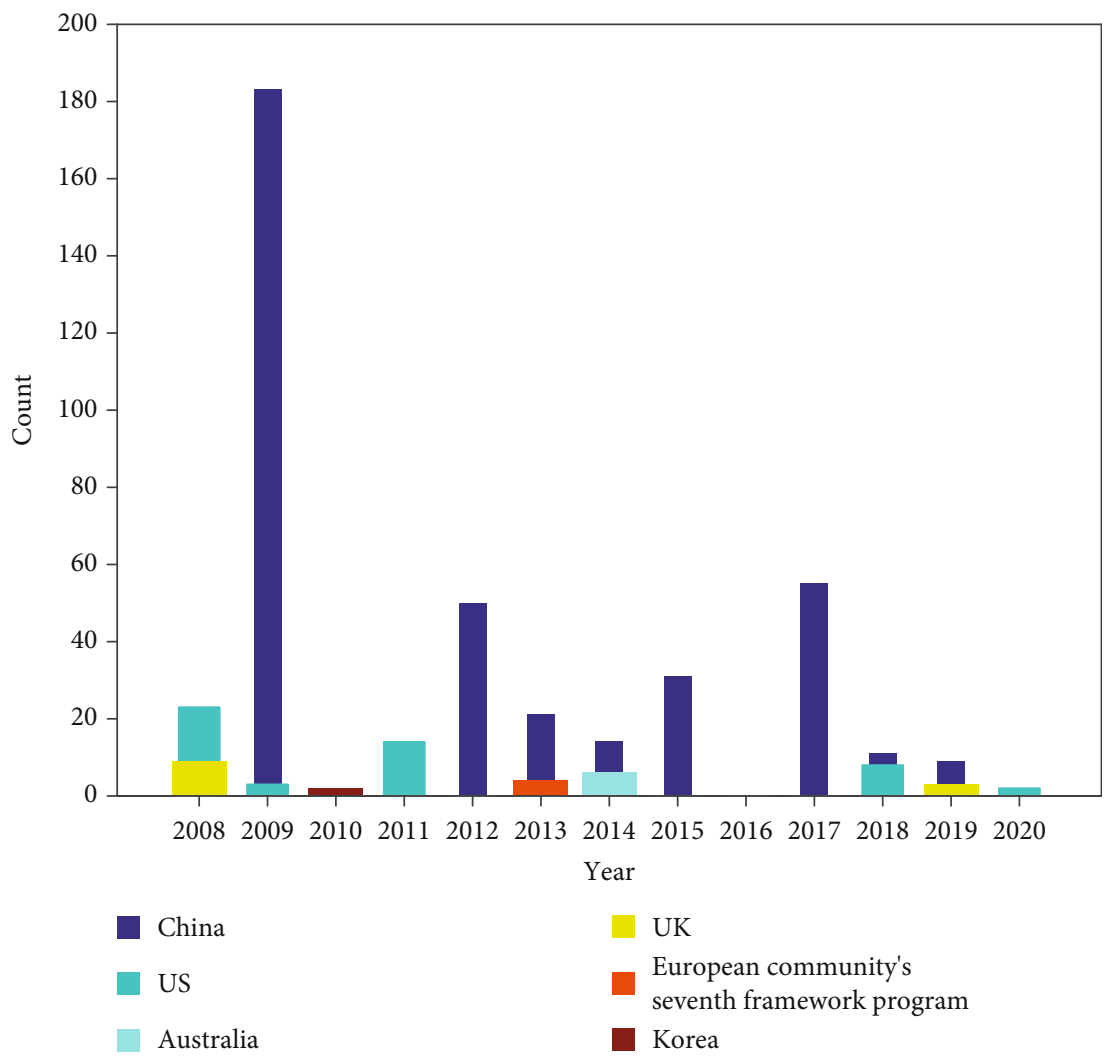

FIgURE 2: The annual number of funding reported from the literature. Annual funding data was from the "FU" field in retrieved literature, and the absence of the "FU" field in literature data made the margin in this figure before 2008. UK is short for the United Kingdom. Except for European Community's Seventh Framework Program, other programs were sorted through countries.

hydrology, and meteorology had also published numerous literature closely related to MODIS LAI/FPAR.

3.3. Coauthorship of Communities. The coauthor network reveals the social connections in the scientific community of this research area. There were 179 connection pairs among 31 countries and 519 connection pairs among 149 institutions (Figure 5). The density of the coauthorship country network was 0.3849 , and that of the coauthorship institution network was 0.0417 . This indicated a close relationship among the cooperating countries and a relatively disperse relationship among the cooperating institutions.

The higher the country in (c) or the institution position in (d) of Figure 5, the larger the output of this community. Countries or institutions closer to the right had better BCD. We found that the USA had the most publications and the highest $\mathrm{BCD}$. This means that, apart from publishing most of the publications, the USA in this research area had very broad cooperation relationships all over the world. China's output ranked second while China's BCD was lower than that of Spain, even though the output of China was far beyond Spain's. As for institutions, CAS had conspicuously more publications and higher BCD than other institutions. Meanwhile, although its output was larger than that of NASA, the BCD of UMD was not comparable to NASA's. We note that NASA showed broad cooperation and influence all over the world.
3.4. Discipline Interactions. There were 107 pairs of interdisciplinary and mutual application relationships among these 25 disciplines. The overall map density was 0.3567 , indicating that the interdisciplinary relationships were relatively close. Environmental sciences and ecology ranked the first with a BCD of 0.52 , which mean that they represented a huge "bridge" to other disciplines that connected broad research areas. Accounting for about one-third of the research frequency in the collected data, the application of the MODIS LAI/FPAR in environmental sciences and ecology had become very common. Moreover, new branches area of research may produce from it.

However, the current applications and research mainly lie in the fields with a strong correlation with the nature of LAI/FPAR, e.g., ecology, environmental science, agriculture, forestry, and water resources. Besides, the existing research hotspots, the fields of extensible applications, and research are rather broad. In terms of the information from the discipline network, the MODIS LAI/FPAR products now have been well applied in many research areas and intersected with several kinds of fields and disciplines. The field of engineering has an indirect connection with agriculture (indirect connection means two nodes are connected through one or more intermediate nodes). We can know accordingly that there is research related to agricultural mechanization. A little branch of "Agricultural Engineering" stretching from "Agriculture, Multidisciplinary" makes evidence for that. 


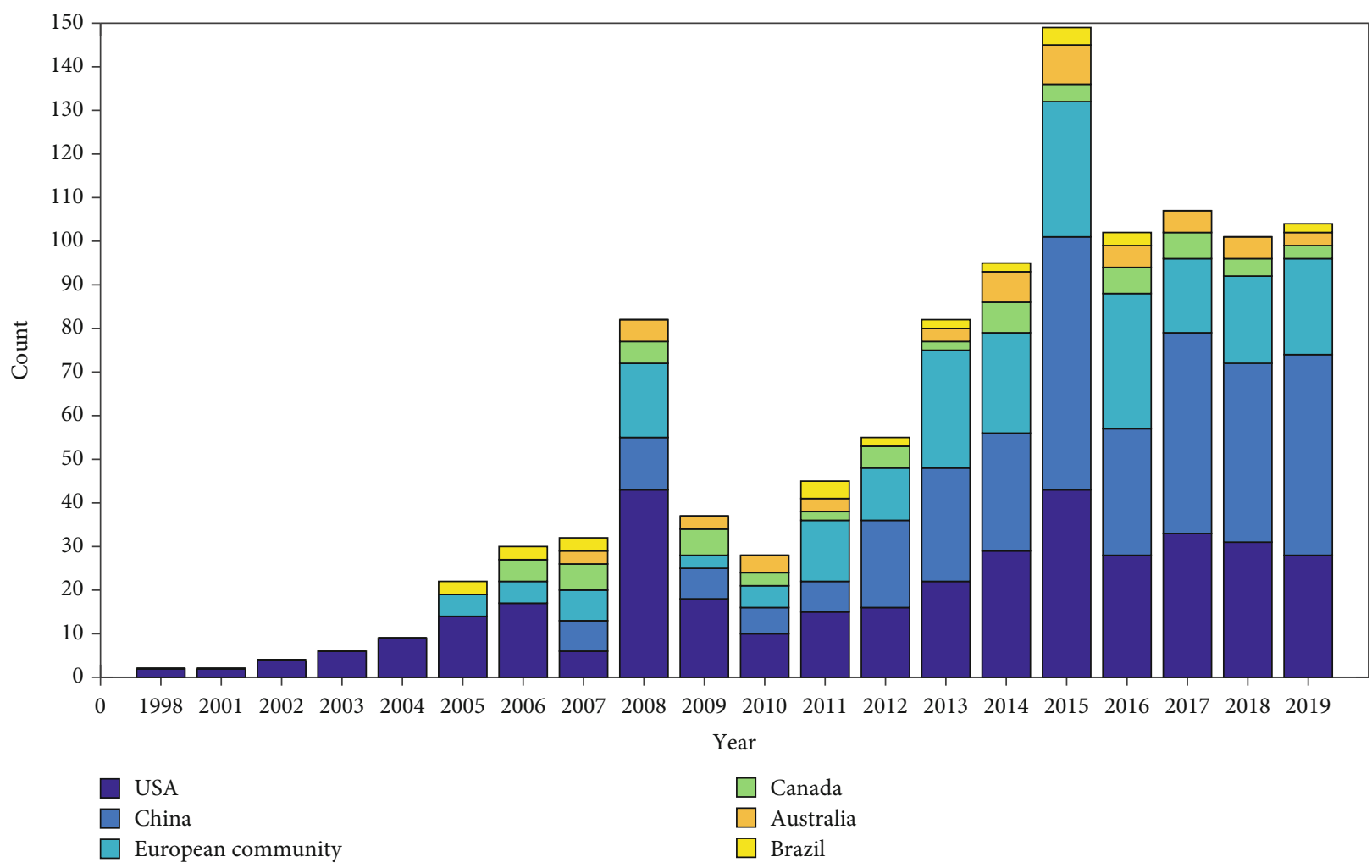

FIGURE 3: Yearly publications of countries over the period 1995-2019. Only years with more than 2 publications were shown in the figure. Publications of Germany, UK, France, Italy, and Spain were combined in the European Community.
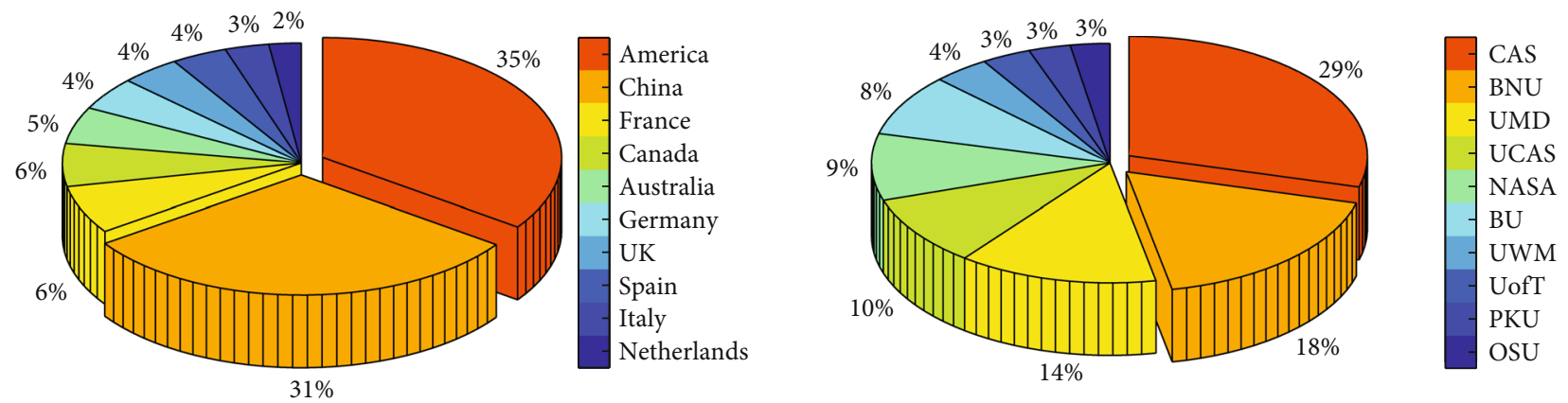

FIgURE 4: Pie chart of publications by countries and institutions over the period 1995-2019. CAS: Chinese Academy of Science; BNU: Beijing Normal University; UMD: University of Maryland; UCAS: University of Chinese Academy of Science; NASA: National Aeronautics and Space Administration; BU: Boston University; UWM: University of Wisconsin; UofT: University of Toronto; PKU: Peking University; OSU: Oregon State University.

For example, Schirrmann et al. [65] introduced a new mobile sensor called Canopy Meter designed for determining LAI while driving over the field. It was the determination of LAI via proximal sensing that supports decision-making processes in precision agriculture and improves biophysical modeling. Experiment results showed that the new proximal sensor represented by Canopy Meter was full of potential to serve for precision agriculture. According to Figure 6, vegetation coverage and types influenced biodiversity conservation. The connections among geophysics, remote sensing, instrumentation, etc. may have a close relationship to radiative transfer studies, algorithms improvement, or sensors upgrading. As for algorithms, the network showed us a prospect in machine learning and artificial intelligence. The discipline of "Water Resources" had relatively strong connections to oceanography and limnology, with a relatively weak connection to "Environmental Sciences \& Ecology." This connection may be strengthened in the future because of the products used in soil and water conservation as well as the connections between groundwater and vegetation. Detailed publications in each discipline have been stored in https:// github.com/DongxiaoZou/Bibliometrics-Data/blob/main/ Discipline.xlsx.

Moreover, researchers may rethink the connections between the MODIS LAI/FPAR not only with natural phenomena but also social phenomena. The tilting towards 
TABLE 1: Top 15 journals publishing papers on the research of MODIS LAI/FPAR.

\begin{tabular}{lrccccc}
\hline & Journal & Recs & TLCS & TGCS & IF & $h$-index \\
\hline 1 & Remote Sensing of Environment & 166 & 2322 & 15169 & 9.626 & 238 \\
2 & Remote Sensing & 104 & 158 & 1483 & 5.001 & 81 \\
3 & International Journal of Remote Sensing & 54 & 180 & 975 & 2.712 & 151 \\
4 & Agricultural and Forest Meteorology & 49 & 190 & 1498 & 5.142 & 144 \\
5 & IEEE Transactions on Geoscience and Remote Sensing & 44 & 724 & 2197 & 6.032 & 216 \\
6 & International Journal of Applied Earth Observation and Geoinformation & 30 & 73 & 471 & 5.391 & 76 \\
7 & Journal of Geophysical Research-Atmospheres & 25 & 307 & 1474 & 4.349 & $\#$ N/A \\
8 & IEEE Journal of Selected Topics in Applied Earth Observations and Remote Sensing & 22 & 44 & 260 & 3.909 & 64 \\
9 & Journal of Geophysical Research Biogeosciences & 20 & 33 & 1368 & 4.225 & $\#$ N/A \\
10 & Journal of Hydrology & 17 & 26 & 421 & 2.137 & 192 \\
11 & ISPRS Journal of Photogrammetry and Remote Sensing & 13 & 19 & 212 & 8.597 & 110 \\
12 & Journal of Applied Remote Sensing & 12 & 0 & 114 & 1.301 & 39 \\
13 & Biogeosciences & 11 & 24 & 244 & 4.194 & 106 \\
14 & Sensors & 11 & 21 & 432 & 3.427 & 132 \\
15 & Journal of Hydrometeorology & 10 & 19 & 171 & 4.767 & 104 \\
\hline
\end{tabular}

${ }^{*}$ Recs represents the literature count published in the journal. Total Local Citation Score (TLCS) represents the cited times in the collection of retrieved literature (905). Total Global Citation Score (TGCS) represents the cited times in the whole Web of Science (WOS) database. Impact Factor (IF) is a fiveyear IF from the Journal Citation Reports (JCR) of 2019. $h$-index is from Google Scholar Metrics, which means there are $h$ publications with at least $h$ citations in this journal, and it is not influenced by extreme values such as an average [64].

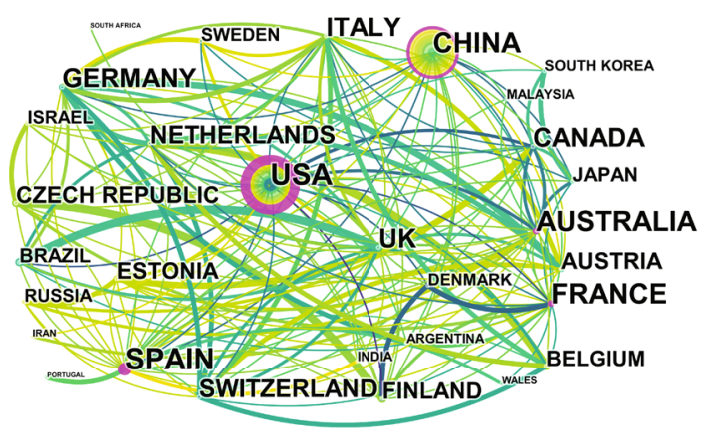

(a)

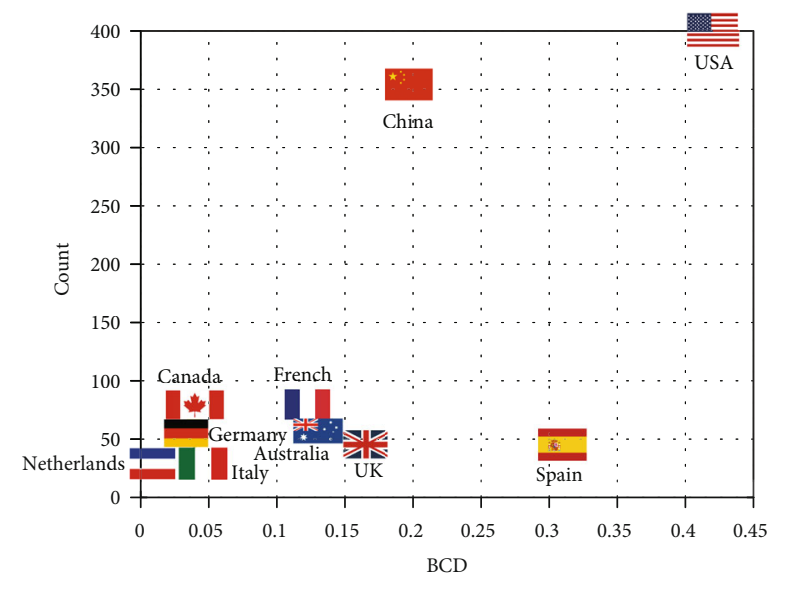

(c)

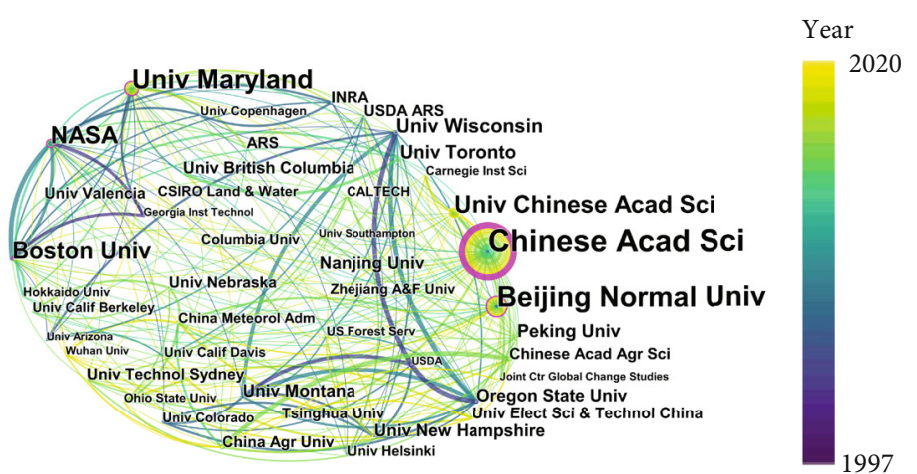

(b)

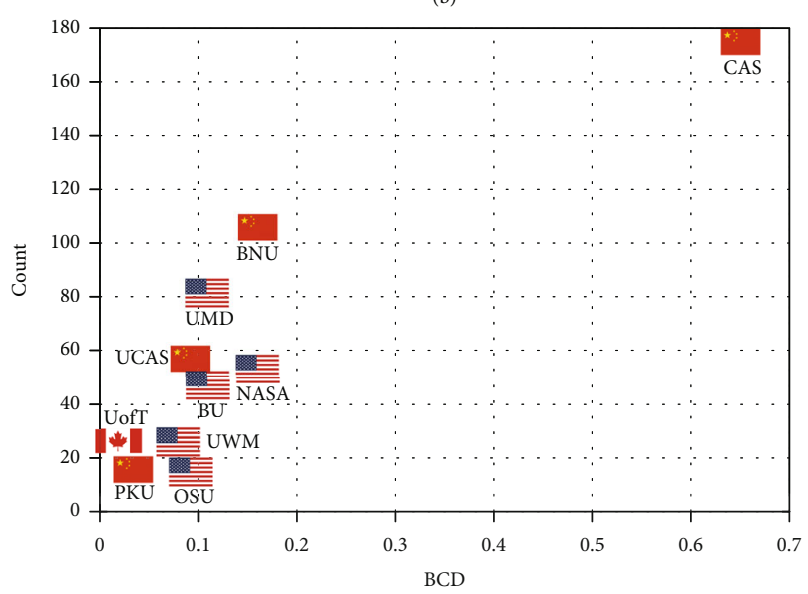

(d)

FIgURE 5: Scientific collaboration networks of (a) countries and (b) institutions. Publications and BCD of the (c) top 10 countries and (d) top 10 institutions. In (a) and (b), every circle represents an individual unit as a whole, and the thickness of the line connecting two individuals directly relates to the strength of their cooperations. The sizes of the font and circles around each institution are positively correlated with their productivity. A vital node with a high BCD is shown in the purple ring (e.g., the USA, Spain, and China). The node with a thicker purple ring means a high $\mathrm{BCD}$ (e.g., the $\mathrm{BCD}$ of the USA is higher than that of Chain). 


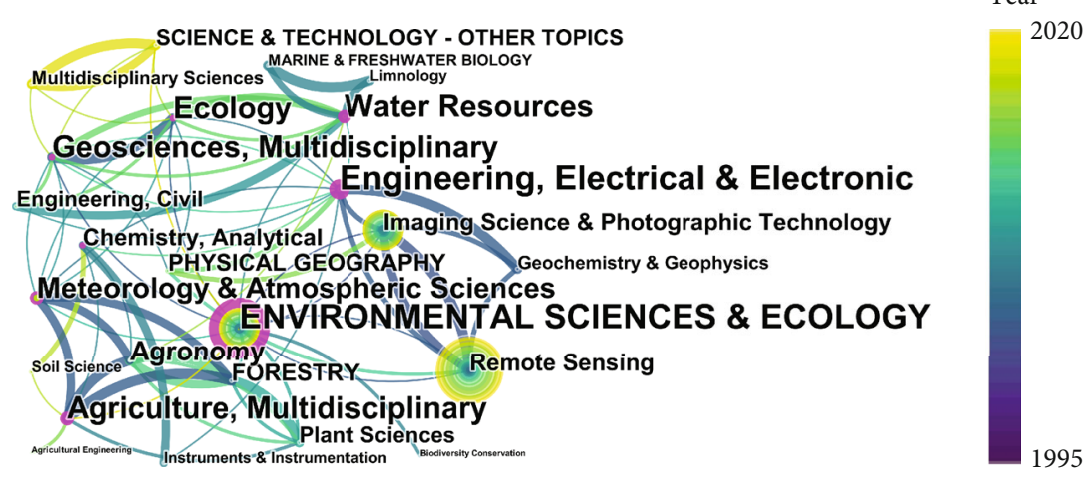

FIGURE 6: Major research areas and connections. Rings represent the years the discipline involved, i.e., a discipline's first appearance, its frequency in other years will add up to the year ring of the original circle, and the thickness of every ring positively correlates to the discipline's frequency of that year. The label size and the node size are positively related to the area involved years and frequency. Circles in purple mean high BCD. A thicker connecting line indicates a stronger correlation between the connecting disciplines.

socioeconomic applications indicated that this discipline development trend and application demands were in line with more mature products. For example, scientists could not only conduct zoological and biological research in conjunction with the livable conditions and habitats of animals [66] but also conduct economic and social studies related to urban development and socioeconomic indicators $[67,68]$. With economic development, policies, and education, there had been a global greening trend [69]. Using the MODIS LAI/FPAR for greenness change detection, talking with the changes of a political idea may lead to a connection with policy. Talking with the "Desert Planting Green Plan" pushed by Alipay may lead to a connection with economics subjects. Talking with the conception transformation in a new generation may lead to a connection with pedagogical subjects, etc. There is great potential or even it can lead to a new revolution when we combine different research fields.

\subsection{Important Research Topics and References}

3.5.1. Keyword Analysis. The coword (feature words or keywords) map is important for analyzing research hotspots and the evolution of hotspots. It can provide prior knowledge for related domain knowledge and cocitation analysis.

The analysis of the keyword co-occurrence mapping knowledge domain yielded a total of 288 keywords. The top 15 keywords are presented in Figure 7, where each square represents a keyword. Except for LAI, MODIS, and FPAR, all the other terms are high-frequency keywords. Among them, the term "evapotranspiration" had the highest BCD of 0.17 ; the term "forest" had the second highest BCD of 0.11. A high BCD keyword node often represents the turning point in the research evolutionary path and the start of a new research subfield [42]. Clustering of the keywords produced nine clusters, which is shown in Table 2.

The keyword cluster tags were generated based on the keywords of literature and the log-likelihood ratio (LLR) algorithm [70]. The tags indicate research hotspots and high-frequency research regions to some extent and provide prior knowledge for the cocitation analysis to be carried out below. For example, cluster "3\# Central Asia" indicated that central Asia was a high-frequency research region in the field. Cluster "8\# Ecosystem Modeling" indicated that the main discipline involved was ecology.

\subsubsection{Cocitation Analysis}

(1) Cluster Analysis. In cocitation clustering, some publications were "recalled" back to the clusters by CiteSpace automatically since they shared citation relationships with other publications in our dataset. The collection contained 834 publications according to clusters generated settings in 2.2.5, i.e., selecting the top 60 most cited rather than all the publications for each year in our collection to generate the cluster map. The cluster labels were generated from the built-in algorithms $[70,90,91]$ of CiteSpace. We applied the above three algorithms to the title, abstract, and keyword of the literature. We selected the top 50 most cited or occurred items from each slice to generate reference tags. Optimal tags on the right in Figure 8 were selected based on the labels generated by the above steps. The cluster numbers were renamed from 1 to 16 for easier correspondence. Figure 8 shows the biggest 16 clusters with their labels attached to the right "1\# Long-term LAI product," "2\# GPP," "3\# Validation," "4\# Crop Growth Model," "5\# Flux Tower," "6\# Radiative Transfer," "7\# Evapotranspiration," "8\# Phenology," "9\# Lidar," "10\# Land Surface Variable," "11\# Deciduous Forest," "12\# PROSAIL model," "13\# Realtime Inversion," "14\# Crop Phenology," "15\# Terrestrial Photosynthesis," and "16\# Vegetation Water Content." There is no clear distinction between clusters. They can be summarized into three types: validation, algorithm and modeling, and application. For better visual clarity, Pisek et al. [82] in cluster "3\# Validation" and Wang et al. [75] in cluster "6\# Radiative Transfer" are not shown in Figure 8. The modularity $Q$ value of citation clustering was 0.7138 , indicating that a good clustering effect and the directions indicated by the clusters can be considered as a reference. Literature with a citation burst usually leads to a new research hotspot in a certain period. If a cluster contains many nodes 


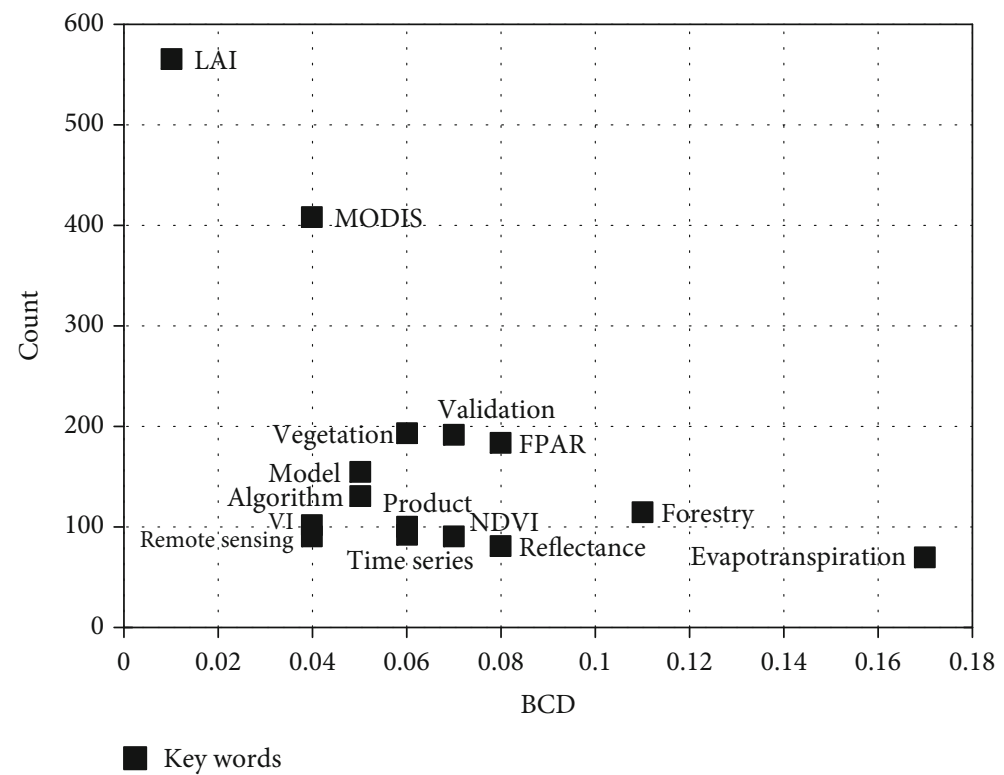

Figure 7: Counts and Betweenness Centrality Degree (BCD) of the top 15 keywords.

TABLe 2: Keyword cluster list.

\begin{tabular}{lc}
\hline$\#$ & Cluster \\
\hline 0 & Eddy covariance data \\
1 & Existing product \\
2 & Vegetation water content \\
3 & Central Asia \\
4 & Data-model comparison \\
5 & Rice crop yield \\
6 & Satellite measurement \\
7 & Multiple sensor \\
8 & Ecosystem modeling \\
\hline
\end{tabular}

*The cluster label with the number 0 to 8 means that the keyword capacity decreases from large to small, namely, the 0\# cluster contains the most keywords, and the 8\# cluster contains the least.

and shows a strong citation burst, then the research direction of this cluster can be regarded as a field hotspot. Figure 9 shows the references with citation bursts that lasted for at least three years; literature that did not use MODIS LAI/FPAR was removed from the list. We here elaborate on the five clusters that show a citation burst (indicated by red nodes) with the assistance of the citation bursts list shown in Figure 9.

(i) Cluster \#1 (Long-term LAI product): the time span of this cluster is from about 2006 to 2018, and the main research results of this cluster are concentrated from 2009 to 2016. It indicates the scholar's work and efforts in improving the length of the time series. Fang et al. conducted validation of the global MOD15 C4, MOD15 C5, and MCD15 C5 products using global field measurement data and confirmed the usability of MODIS C5 [26]. C6 was released and distributed free of charge to the public from August 2015. Its RMSE decreased from 0.80 of C5 down to 0.66 . The improvement benefitted from better quality input data according to the comprehensive evaluation of the new collection of the MODIS LAI/FPAR products (MOD15A2H) through validation with field measurements, intercomparison with other LAI/FPAR products, and comparison with climate variables in Yan et al. [27]. With the broadly validated MODIS LAI/FPAR, Xiao et al. used general regression neural networks to generate the GLASS LAI product with a trusted data source, which is a relatively long-term LAI product [85]. Two years later, Xiao et al. improved the previous method and assessed the quality and accuracy to confirm the usability of the GLASS LAI product [89]. This successful attempt in data generation and data improvement has laid the data basis for the subsequent research. The validation of the MODIS LAI/FPAR products made them a reference to other research areas. As one of the most broadly used LAI products, MODIS LAI/FPAR products were also used for evaluating other LAI products or used as one of the inputs for other algorithms [4, 87, 88]. Among these validations, Yan et al. used climate variables to explain the interannual variations of LAI/FPAR, which set an example of a novel approach in indirectly evaluating these products [27]. In the meantime, researchers have paid more attention to the time integrity of LAI/FPAR products, especially for global climate change studies

(ii) Cluster \#2 (GPP): the main outbreak time span of this cluster is from 1998 to 2012. The important publications in this cluster are Turner et al. and 


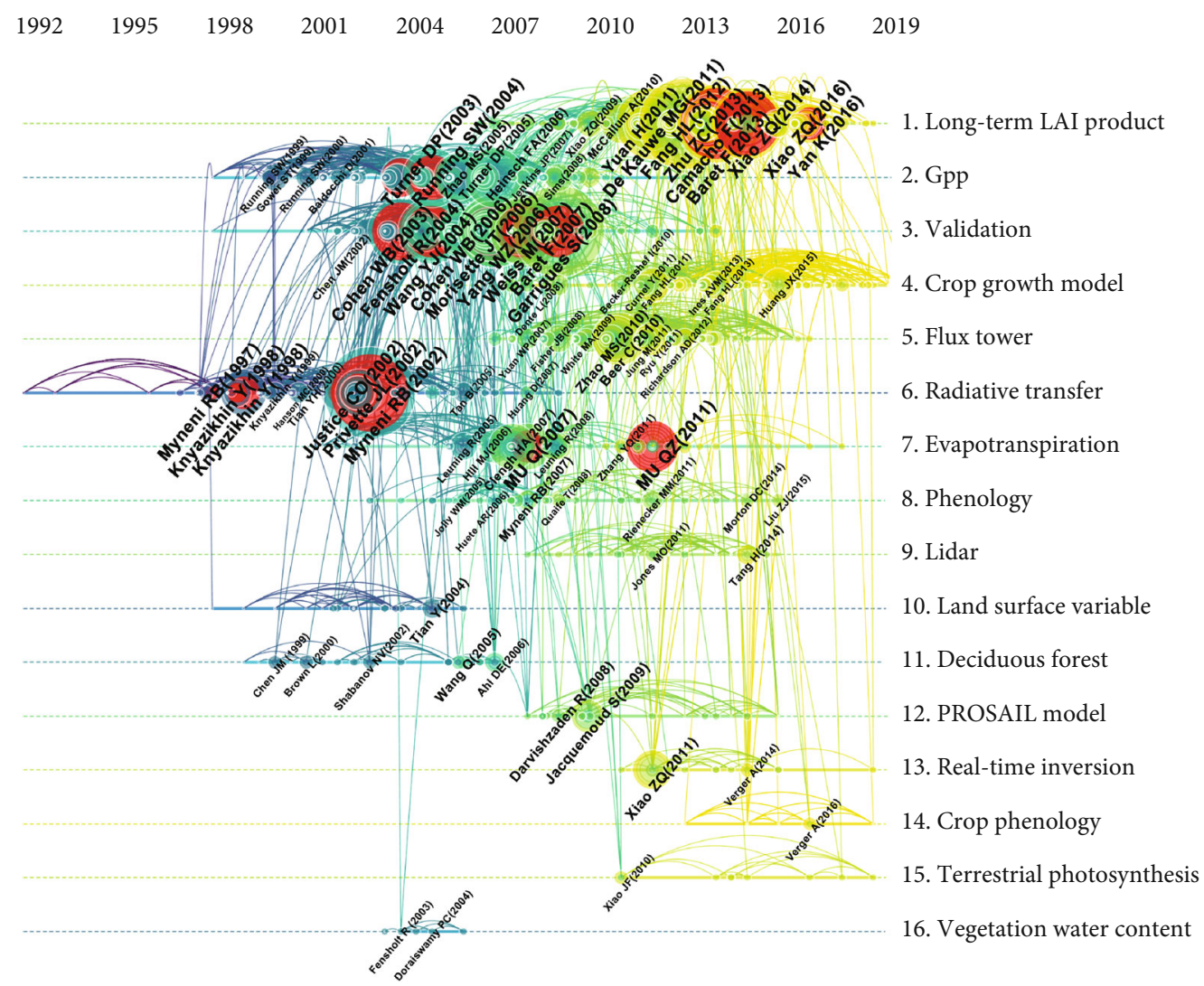

FIgURE 8: A timeline view of MODIS LAI/FPAR publications. Splines linking two nodes in the figure indicates that there is a cocitation relationship between both nodes. The larger nodes correspond to the years with more citations, and the thickness of every ring is positively correlated to the number of citations of that year. The red nodes are the detected bursts in literature. The time increases from left to right by year. The publication year gradually increases from purple to yellow, purple published first, blue later than green, and yellow published latest. GPP means gross primary productivity.

Running et al., both with a burst strength of about 10 $[11,71]$. In this set of studies, the MODIS LAI/FPAR products were mainly used for primary productivity estimation. The cluster label implies that the studies were related to monitoring ecosystem dynamics with GPP retrieved from MODIS LAI/FPAR products. Additionally, inputting different LAI datasets into an ecosystem model to estimate GPP (or ET) can also be a way to validate the quality of different LAI products $[92,93]$.

(iii) Cluster \#3 (Validation): the duration of this cluster is from 1998 to 2013 with numerous milestone studies during the period 2002 to 2008. Most of the research in this cluster is field verification, algorithm evaluation, and validation of LAI/FPAR products. This cluster represents the research directions that focus on the validity and suitability of the products. Cohen et al. made a quality assessment of 2000/2001 provisional MODIS products for four sites in North America, evaluated both the MODIS land cover product quality and MODIS LAI product quality in 2003 [76]. In the following year, Fensholt et al. evaluated the MODIS LAI/FPAR and the relation between FAPAR and NDVI in a semiarid environ- ment using in situ measurements [79]. In the same year, Wang et al. evaluated the MODIS LAI algorithm at a coniferous forest site in Finland [78]. In 2008, Garrigues et al. investigated the performances of four major global LAI products at $1 / 11.2^{\circ}$ spatial sampling and a monthly time step, MODIS C4 (main algorithm, from MODIS/TERRA) included [83]. In a complete life cycle of LAI products, validation is always one of the most important links. Effective validation over one product can help it avoid becoming "data trash" and make researchers exploit its applicability. Therefore, LAI validation infrastructure, analysis, and use of extensive validation stations with high acceptance are of significance. Validations over heterogeneous surfaces and sloped terrains are also still in demand

(iv) Cluster \#6 (Radiative Transfer): The time span of this cluster is from 1992 to 2008 according to the timeline view; it belongs to a relatively early research cluster. The cluster captures the efforts on improving models to retrieve precise LAI estimates within a certain period. It has a close relationship with the "12\# PROSAIL model" through citation. The PROSAIL model is a model that couples the 

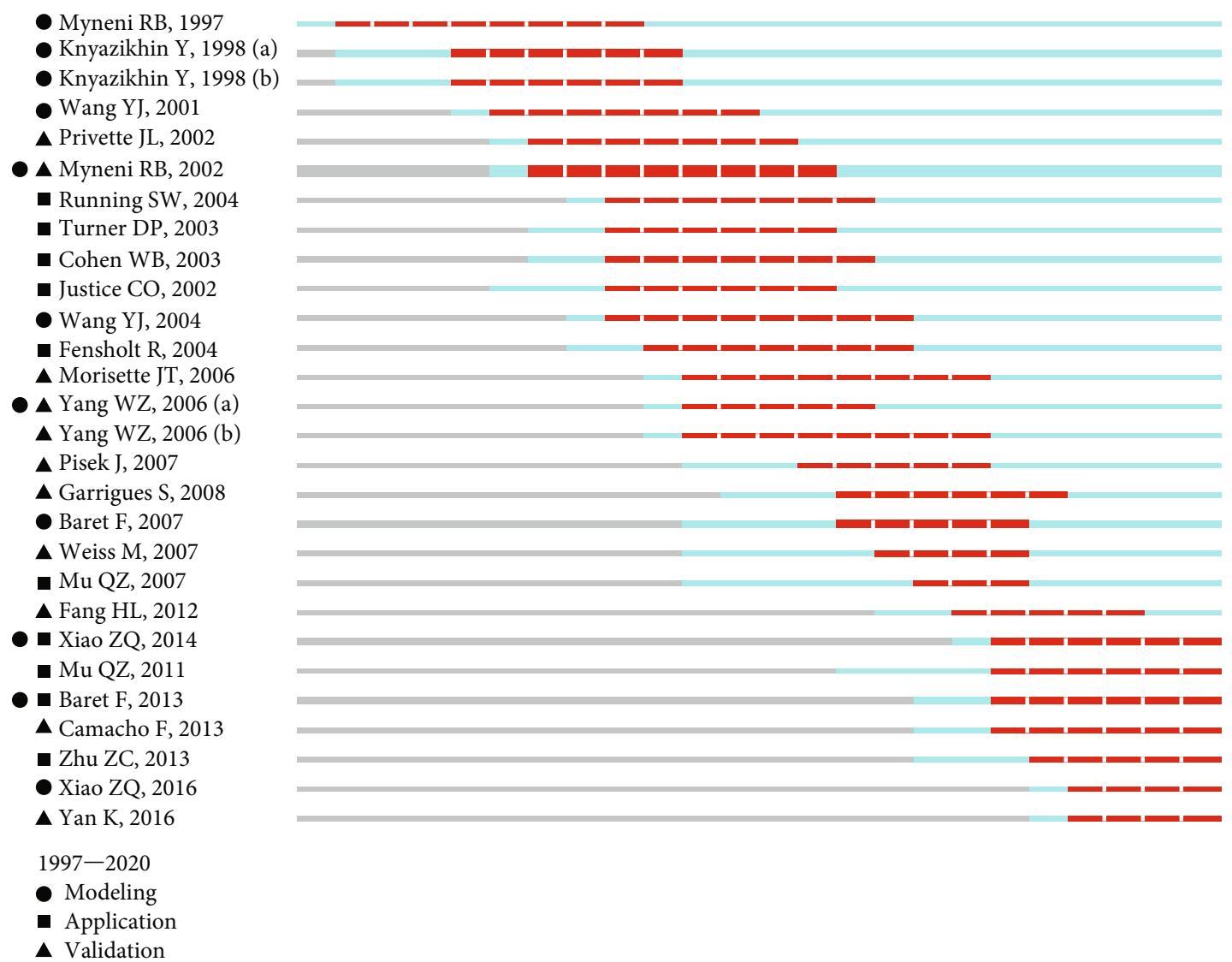

Figure 9: References with citation bursts of at least three years [1, 2, 4, 11, 21, 24-26, 31, 71-89]. A circle, triangle, or square in front of the publications indicates that the publications belong to algorithm or modeling, verification, and application types, respectively. Every publication is published at the beginning of the blue line. The red segments represent the explosive citation period; one segment represents one year. A thicker line indicates a higher burst strength. The burst literature is highlighted in the timeline map with red nodes.

"PROSPECT" model and the "SAIL" model [94], which is an important model in the vegetation radiative transfer model. In this cluster, Myneni et al. had a seven-year outbreak with a burst strength of 9.8 [72]. This paper proposed an algorithm for the estimation of LAI and FAPAR from atmospherically corrected NDVI observations [72]. Although it did not directly use MODIS LAI/FPAR data, it provided an algorithm basis for the MODIS LAI/FPAR products' production. Knyazikhin et al. inversed the radiative transfer model with a LUT $[73,74]$. He retrieved LAI and FPAR from canopy reflectance data provided by the MISR and MODIS instruments. These studies have laid the research foundation for countless scholars who study radiation transmission and LAI retrieval. The paper by Myneni et al. has the strongest burst strength of all the burst literature [1]. Its citation burst lasted from 2003 to 2010, and the outbreak lasted seven years. This literature evaluated the performance of the MODIS LAI/FPAR algorithm and verified the LAI/FPAR products, proving the high performance and credibility of its algorithm and products. At the same time, users were informed of the uncertainties of the algorithm and products, which played a positive role in promoting the use of MODIS LAI/FPAR products

(v) Cluster \#7 (Evapotranspiration): The time span of this cluster is from 2001 to 2017. This label coincides with the high-frequency and high BCD keyword "Evapotranspiration", which is a major application field of the MODIS LAI/FPAR products. Using the MODIS LAI/FPAR products to calculate evapotranspiration has been a long-lasting research hotspot that contributed to both land and water management, to optimize limited water supplies as well as to reduce the cost of irrigation projects. In 2011, Mu et al. showed an 11.7 strength [86]. This paper identified problems in the ET algorithm in $\mathrm{Mu}$ et al. [31], and improved the earlier algorithm. The authors improved the MODIS global terrestrial evapotranspiration algorithm with MOD15A2 FPAR as vegetation cover fraction data to partition the net radiation between the canopy and the soil surface. This improved MODIS ET algorithm was submitted to NASA and the dataset was updated through 2010 
Other clusters show additional research applications based on the MODIS LAI/FPAR products. For example, "5\# Flux Tower" and "0\# Eddy Covariance Data" in the keyword clusters indicate a high correlation in the MODIS LAI/FPAR products with ecological studies. The literature in cluster "4\# Crop Growth Model" and "14\# Crop Phenology" together with the keyword cluster "5\# Rice Crop Yield" indicates that the MODIS LAI/FPAR products are of great significance in food crop production estimation.

(2) Research Evolution Analysis. Looking at the timeline of research clustering, we can speculate the migration of research hotspots. We used 2007 as the separation time point. Before 2007, "2\# GPP," "6\# Radiative Transfer," "10\# Land Surface Variable," "11\# Deciduous Forest," and "16\# Vegetation Water Content" clusters show aggregation. After 2007, the clusters including "1\# Long-term LAI product," "4\# Crop Growth Model," “5\# Flux Tower," “9\# Lidar,” “12\# PROSAIL Model," "13\# Real-time Inversion," "14\# Crop Phenology," and "15\# Terrestrial Photosynthesis" show relative aggregation. Clusters " $3 \#$ Validation" and " 8 \# Phenology" span a long timeline and do not take 2007 as an obvious dividing line.

The development of the MODIS LAI/FPAR products may follow the four stages of a scientific discipline according to Shneider et al. [95]. A specialty may experience the initial conceptualization stage, the growth of research capabilities through the flourishing of research tools, the expansion stage when researchers apply their methods to subject domains beyond the original research problems, and the final stage of decay $[41,95]$.

We found that at the very beginning most of the publications were about algorithms research. To estimate LAI and FPAR more accurately, researchers perfected the models over and over. It is not surprising that early studies focused on the initialization of sensors and algorithms, which helps data acquisition. As the models improved enough, applications more closely connected to the nature of LAI and FPAR have appeared, and some algorithms for these applications have been developed. For a period, LAI/FPAR models and application algorithms have been perfected, and new applications have been derived. Afterward, with the tools and instruments established, there has been a gradual shift to holistic studies, algorithms upgrades, and MODIS LAI/FPAR product upgrades. As the data demands increased, researchers focused on data quality and generating LAI products with long time series, better temporal continuity, and spatial completeness. In this process, validations of algorithms and products prevailed. Some researchers worked on validation to improve the applicability of the data and to makes the accuracy explicit, which laid down a basis for the following research. Scientists always demand longer time series, higher accuracy, higher temporal resolution, and higher spatial resolution. Connected research has never stopped. Until recently, the applications tend to be related to practical resources management (e.g., in agriculture). The timeline view cluster labels of agriculture, crop growth model, and real-time inversion are evidence for this. Turning points in research could indicate the maturity of technologies, the appearance of new applications or new analysis methods, or proposals for new demands [42]. Based on the changing patterns above, we can take a glance at the history of MODIS LAI/FPAR products. We firmly believe that the MODIS LAI/FPAR products will bring more surprises to the whole scientific community in the near future.

The cocited timeline view provides an intuitive knowledge map for scientists to understand the research hotspots. Some information may have been omitted in this paper but readers can obtain more details according to the timeline view.

3.6. Algorithm Development. There are some publications with no keywords such as MODIS LAI/FPAR, but they are indeed related to research on the process of algorithm development, product application, and so on. To make up for the search omission of MODIS LAI/FPAR algorithm developments, we conducted an additional search for algorithm development. Based on the retrieved data, we execute keyword time zone partition and cocitation clustering in CiteSpace.

Figure 10 shows the relatively high-frequency keywords arranged by time order. We can easily identify several keywords that have been a relatively high-frequency keyword for couples of years: Radiative Transfer (RT), forest, leaf area index, reflectance, MODIS, model, vegetation, Spectral Invariant (SI), Photon Recollision Probability (PRP), algorithm, etc. Following the keyword time zone view and tracing the variation of the keywords in the publications, we can find that the research derived from the algorithms is more and more extensive.

Similar to the publication timeline view of Figure 8, there is no clear delimitation between clusters in Figure 11. Because of the citing relationship, some publications not in our original dataset were added automatically by CiteSpace in this map, too. Adding those publications, the publication time is from 1986 to 2020, which is shown as the color bar from purple to yellow. Figure 11 contains the clusters with the closest cocitation relationship. The sporadic clusters around this main body were omitted to ensure the conciseness of the figure; so, the serial number of clusters in Figure 11 is discontinuous. There are clear clusters with a relative high Modularity $\mathrm{Q}$ value of 0.8523 .

By recognizing the color block with the cluster label, readers can take a glance at research themes by years. It is not difficult to find that modeling LiDAR waveform, aboveground biomass, open-canopy forest, broadleaf forest, woody material, understory reflectance, and canopy height are research themes of the relatively early years. Chemical properties, leaf specular reflection, and fluorescence correction vegetation index are the latest research flow. The theme "forest reflectance model" covers several periods, and research on it seems to be still ongoing.

SRT was originally developed from a stochastic approach in cloud physics [96-98]. The method treats the 3D canopy structure as a stochastic process of space and describes it with the indicator function [19]. It first estimates the 3D radiative field in the vegetation canopy, then calculates the average, and lastly outputs the ensemble average radiance and higher 


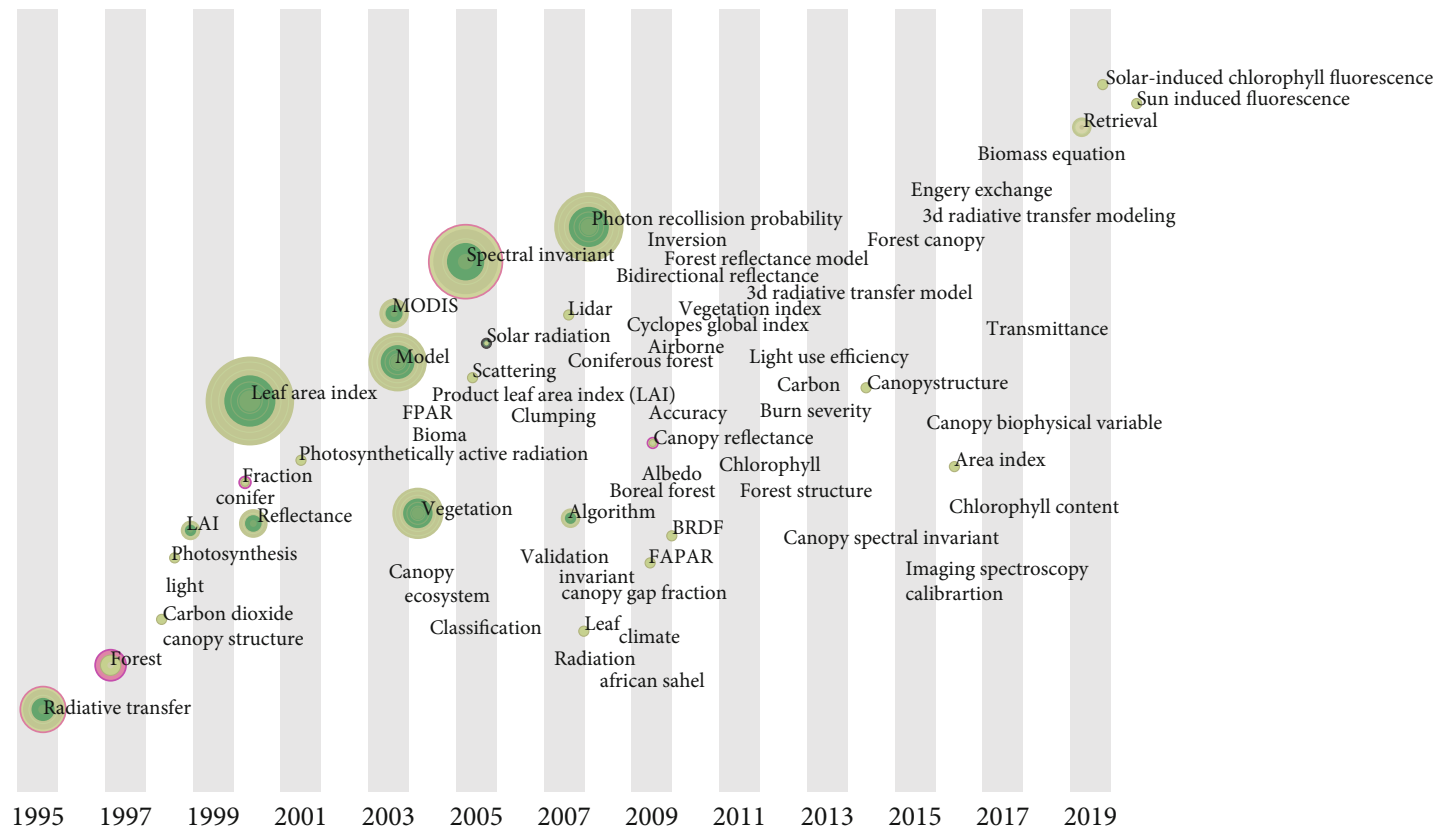

Figure 10: Keyword time zone view. The corresponding time of a keyword's first letter in vertical is the first show-up year of that word. Rings represent the years and the word appearances, i.e., a keyword's first appearance, its frequency in other years will add up to the year ring of the original circle, and the thickness of every ring positively correlates to the keyword's frequency of that year.

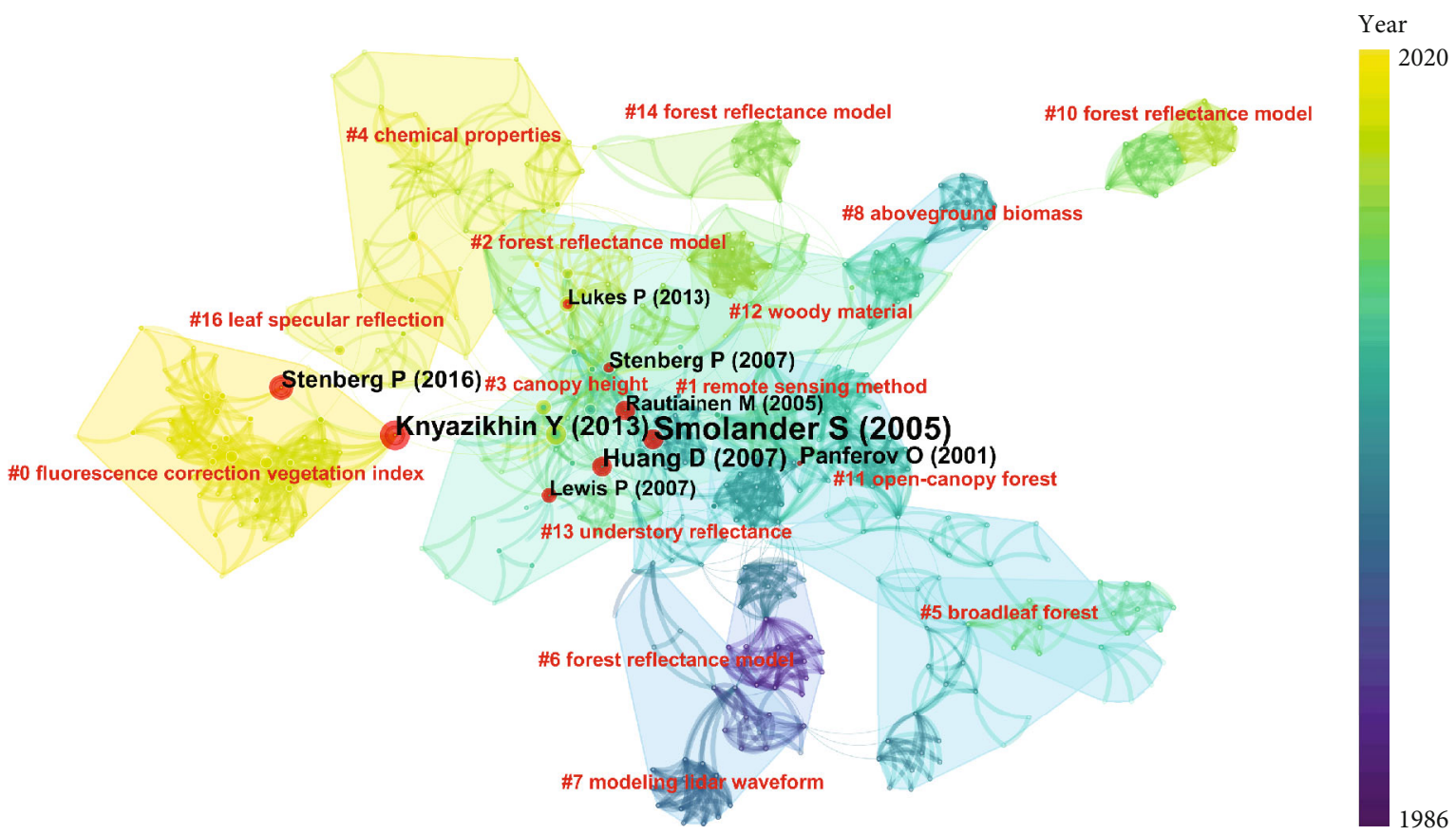

FIGURE 11: Cocitation cluster map of the MODIS LAI/FPAR algorithm. Publications with bursts of citations are highlighted in red; their burst strength ranges from about five to eight.

statistical moments. This makes RT models sensitive to $3 \mathrm{D}$ effects of the canopy structure and meanwhile be of increased computing efficiency $[19,99]$, comparing favorably with the accuracy of 3D RT and the computational efficiency of 1D RT. "Spectral Invariants Theory" (SIT) is another core of the MODIS LAI/FPAR algorithm. It states that the amount of radiation absorbed by a canopy depends only on the wave- length and a wavelength-independent parameter describing the canopy structure [100], i.e., simple algebraic combinations of leaf and canopy spectral transmittance and reflectance are wavelength-independent [101]. Thus, it is used for reducing the LUT dimensionality and ensures the algorithm's computational efficiency. The success of the MODIS LAI/FPAR products also contributed to continued research and improvements 
to these algorithms in the scientific community. Cescatti et al. used a 3D RT model to examine the effects of hierarchical levels of needle clumping on the canopy transmittance of a conifer stand [102]. Panferov et al. conducted empirical and theoretical analyses of spectral hemispherical reflectances and transmittances of individual leaves and the entire canopy sampled at equatorial rainforests and temperate coniferous forests [103]. This research provides evidence for canopy SRT and underlies the operational algorithm of the MODIS LAI/FPAR products. Rautiainen et al. [104] proposed a simple parameterization model PARAS for taking into account the effect of within-shoot scattering on coniferous canopy reflectance, confirming the efficiency of PRP in multiple scatterings at the small scale. Almost at the same time, through empirical analyses of spectral canopy transmittance and reflectance collected during a field campaign in Flakaliden, Huang et al. systematically proved the validity of the theoretically derived spectral invariant relationships reported in the literature [101]. Lukeš et al. used imaging spectroscopy data to conduct an empirical test of the SRT, concluding that in coniferous canopies, the SRT performs well in the near-infrared spectral range [105]. In 2012, Knyazikhin et al. applied SRT in foliar nitrogen content research, introduced the directional area scattering factor, and proposed that the bidirectional reflectance factor is less relevant to the foliar nitrogen content with the canopy structure elimination [106]. This study led to the application of SRT in related research. In 2016, Stenberg et al. systematically explained how SRT is related to PRP and to canopy structural variables and introduced other spectral invariants to quantify the directionality of canopy scattering [100]. This paper reviewed the advances in the theoretical development of the PRP concept.

With the development of fluorescence remote sensing and heterogeneous surface modeling, in recent years, SRT and SI aroused the attention of scholars again. Based on the output parameters of the SRT model, Zeng et al. proposed the analytical fluorescence RT model to investigate the effects of the canopy structure and observation geometry on solarinduced chlorophyll fluorescence (SIF) [107]. This coincides with the keyword "solar-induced chlorophyll fluorescence," "sun-induced fluorescence," and the latest research cluster "0\# fluorescence correction vegetation index." Further, Li et al. used the SRT model to study the heterogeneous distribution of damaged leaves in agriculture, leading the way to potential future quantitative retrievals of damaged vegetation [34]. It is foreseeable that the algorithms of MODIS LAI/FPAR will drive research for several more years.

\section{Discussion and Conclusion}

On the occasion of the 20th anniversary of the Terra mission and the MODIS LAI/FPAR project, this paper is aimed at providing a summary of the development trends, scientific collaborations, involved disciplines, research hotspots, and algorithm development of the MODIS LAI/FPAR products. An objective analysis of the history and dynamics of this research area allows identifying new research avenues for these products.
The research based on the MODIS LAI/FPAR products has been increasing with a multiyear average growth rate of $24.9 \%$ in publication. The publications using these products increased from 226 in 2009 to over 900 by 2019. China and the USA were the backbone of this research area, among which CAS was the most important research institution, both in terms of publications and international cooperation. Apart from that, BNU, BU, UMD, UCAS, and NASA were other backbone forces in this field. Countries, institutions, and authors with more publications had better overall cooperation, while "working alone" was rare.

Research based on the MODIS LAI/FPAR products covered a wide range of disciplines, but mainly focuses on environmental science, agriculture, forestry, water resources, and ecology, which have a strong correlation with LAI/FPAR. Besides, the existing research hotspots, related applications, and research are rather broad according to the discipline network. Connecting very different disciplines has more potential to lead to new research directions. Apart from the observation of the discipline network and its connections, scientists can also benefit from the discipline network and produce new research ideas. Similar studies and methods can be applied for other global moderate resolution LAI products, e.g., GEOV*/GLASS/GLOBMAP, in order to derive an overall idea of the life cycle of the global LAI products.

LAI algorithms, data evaluation and validation, and agricultural production assessment were high-frequency research hotspots related to MODIS LAI/FPAR. Broadening the research field both in disciplines and study areas, improving the algorithm, and breaking the existing difficulties will be the trend of future research. First, validation is a longlasting topic that shows a high correlation with the release of new data collections. Time series validation over LAI/FPAR [28] and validation of LAI/FPAR with its application $[92,93]$ are being paid more and more attention. Validation research in different areas of terrain and vegetation coverage is always of significance. On the one hand, this could provide a foundation for other research. On the other hand, objective and comprehensive product quality information may contribute to its usage, as in this process researchers help improve the product quality in return in a virtuous cycle. Noticeably, there are much fewer FPAR validation and application studies compared to LAI. Strengthening FPAR studies is of great significance and will be one of the future directions. Secondly, overcoming the existing difficulties related to surface heterogeneity, scale effects, and sloped terrain, which can affect the accuracy of LAI/FPAR will be the work direction of some researchers. Other existing difficulties (e.g., data acquisition difficulties and data errors caused by cloudiness and rainy weather and accurate studies on mountains, wetlands, tropical rain forests, Qinghai-Tibet Plateau, and other regions with special climate and topography.) also seized more research attention. Thirdly, whether for simply pursuing algorithm improvement or applying LAI/FPAR as input to calculate other variables, the accuracy of LAI/FPAR products is positively correlated with the accuracy of the research. Therefore, algorithm research on LAI/FPAR will be a research hotspot for a period to come. At the same time, as we entered the big data era, with the rapid development of 
machine learning and artificial intelligence, algorithm research combined with machine learning may become another trend in this subresearch field. Further, the life of the MODIS sensor has far exceeded its designed specification. With the advancement of new sensors in multiple dimensions of time resolution, spatial resolution, and spectrum, it is also urgent to develop algorithms suitable for specific sensors. Developing new algorithms is both a challenge and an opportunity for this area. Developing algorithms to better understand and model the scale dependence of LAI/FPAR estimation using current data such as Sentinel-2/Sentinel-3 and Landsat could help to improve the data archives from medium resolution sensors. Another challenge is to ensure the long-term continuity of the valuable Earth System Data Records (ESDRs), NASA, and NOAA, and the military jointly launched the JPSS-VIIRS (JPSS: Joint Polar Satellite System, VIIRS: Visible Infrared Imaging Radiometer Suite) projects. The VIIRS instrument was designed with a strong MODIS heritage. The development of a continuous, consistent, and well-characterized VIIRS LAI/FPAR dataset is critical to continue the MODIS time series [33, 108-110]. Some studies evaluated the VIIRS LAI/FPAR products through comparisons with the MODIS LAI/FPAR products in terms of both spatial and temporal patterns $[16,33]$. In this context, the new LAI/FPAR dataset will provide impetus to new research. The consistency and heritage of VIIRS LAI/FPAR and MODIS LAI/FPAR will keep the series products alive and provide valuable datasets for the scientific community.

However, we recognize some limitations in this paper that mainly results from the research peculiarity and the limitations of the analysis tools. Even though we have reduced the data error by using a precision retrieval strategy and artificial data cleaning, there are still some "error publications" recalled by the analysis tool. Because they were highly cited by other papers in our dataset, these "error publications" were classified as the data that meet our needs. These publications will not influence the statistical trends but will disturb the research trend analysis to some degree. Also, there might be some documents that have not been retrieved. We used the "TS" (means topic) as the field tag to retrieve papers in our search criteria. This tag could search the field of title, abstract, author keywords, and keywords plus within a record. As long as one of the search terms appearing in any of the above fields, the paper would be recorded in the result, whereas when the terms we used did not show up in any of the above fields but show up in the paper's main body, and the "needed paper" would escape from searching. Of course, as the "error publications" mentioned above, some of these omissive "right publications" could be "recalled" to our dataset in the same way. Another, funding data retrieved from the literature was identified by the "FU" field in the WOS literature information. According to information from the "FU" field, we gained funding data including foundation name, unit, and country. The absence of the "FU" field in some publications makes the analysis inadequate regarding the funding data. That is the reason why the funding number gained from literature was much lower than the number of publications. In addi- tion, there was some inappropriateness in classifying publications according to labels on the right of the timeline view. For example, Jacquemoud et al. was classified in the cluster " $8 \#$ Phenology", but a manual review shows that it is not strongly connected with phenology; so, we moved it to the more appropriate cluster "12\# PROSAIL Model" with its topology unchanged [111]. It is unavoidable that some misclassified publications still exist. Furthermore, to highlight some important publications, we canceled some subdominant nodes that covered the former ones in the timeline view, which is described in detail in the section on the cluster analysis. Bibliometric analysis tools are very sophisticated tools for scientific mapping, providing efficient, and effective visualizations based on scientific algorithms and mapping methods. We are deeply grateful to them for the support they provided in the bibliometric visualization analysis. Hopefully, their limitations can be overcome in the future.

\section{Conflicts of Interest}

The authors declare that there is no conflict of interest regarding the publication of this article.

\section{Authors' Contributions}

K. Y performed the conceptualization, methodology, writingreview and editing, and funding acquisition. D. Z performed the formal analysis, writing-original draft, and investigation. G. Y. and H. F. performed the formal analysis and investigation. M. W., M. R., Y. K., and R. B. M. performed the methodology, conceptualization, supervision, and resources. All authors have read and agreed to the published version of the manuscript.

\section{Acknowledgments}

This work was supported by the National Natural Science Foundation of China [grant number 41901298], the Open Fund of State Key Laboratory of Remote Sensing Science [grant number OFSLRSS201924], the Open Research Fund of Key Laboratory of Digital Earth Science, Institute of Remote Sensing and Digital Earth, Chinese Academy of Sciences [grant number 2018LDE002], and the Fundamental Research Funds for the Central Universities [grant number 2652018031].

\section{Supplementary Materials}

Table S1: funding information gained from "FU" field in retrieved literature. (Supplementary Materials)

\section{References}

[1] R. B. Myneni, S. Hoffman, Y. Knyazikhin et al., "Global products of vegetation leaf area and fraction absorbed PAR from year one of MODIS data," Remote Sensing of Environment, vol. 83, no. 1-2, pp. 214-231, 2002.

[2] M. Weiss, F. Baret, S. Garrigues, and R. Lacaze, "LAI and fAPAR CYCLOPES global products derived from 
VEGETATION. Part 2: validation and comparison with MODIS collection 4 products," Remote Sensing of Environment, vol. 110, no. 3, pp. 317-331, 2007.

[3] I. Mccallum, W. Wagner, C. Schmullius, A. Shvidenko, and S. Nilsson, "Satellite-based terrestrial production efficiency modeling," Carbon Balance and Management, vol. 4, no. 1, p. $8,2009$.

[4] F. Baret, M. Weiss, R. Lacaze et al., "GEOV1: LAI and FAPAR essential climate variables and FCOVER global time series capitalizing over existing products. Part1: principles of development and production," Remote Sensing of Environment, vol. 137, pp. 299-309, 2013.

[5] R. K. Y. Myneni and T. Park, "MCD15A3H MODIS/Terra +Aqua Leaf Area Index/FPAR 4-day L4 Global 500 m SIN Grid V006 [Data Set]," 2015, October 2017, https://search .earthdata.nasa.gov/search.

[6] P. Mason, J. Zillman, A. Simmons et al., Implementation Plan for the Global Observing System for Climate in Support of the UNFCCC (2010 Update), World Meteorological Organization, Geneva, Switzerland, 2010.

[7] Y. Knyazikhin, J. Glassy, J. L. Privette et al., MODIS Leaf Area Index (LAI) and Fraction of Photosynthetically Active Radiation Absorbed by Vegetation (FPAR) Product (MOD15) Algorithm Theoretical Basis Document, 1999, http://eospso.gsfc .nasa.gov/atbd/modistables.html.

[8] P. Sellers, R. E. Dickinson, D. Randall et al., "Modeling the exchanges of energy, water, and carbon between continents and the atmosphere," Science, vol. 275, no. 5299, pp. 502509, 1997.

[9] S. D. Prince and S. N. Goward, "Global primary production: a remote sensing approach," Journal of Biogeography, vol. 22, no. 4-5, p. 815, 1995.

[10] F. Veroustraete, H. Sabbe, and H. Eerens, "Estimation of carbon mass fluxes over Europe using the C-fix model and Euroflux data," Remote Sensing of Environment, vol. 83, no. 3, pp. 376-399, 2002.

[11] S. W. Running, R. R. Nemani, F. A. Heinsch, M. Zhao, M. Reeves, and H. Hashimoto, "A continuous satellitederived measure of global terrestrial primary production," Bioscience, vol. 54, no. 6, pp. 547-560, 2004.

[12] C. Potter, S. Klooster, P. Tan, M. Steinbach, V. Kumar, and V. Genovese, "Variability in terrestrial carbon sinks over two decades: Part 2 - Eurasia," Global \& Planetary Change, vol. 49, no. 3-4, pp. 177-186, 2005.

[13] I. Mccallum, W. Wagner, C. Schmullius et al., "Comparison of four global FAPAR datasets over Northern Eurasia for the year 2000," Remote Sensing of Environment, vol. 114, pp. 941-949, 2010.

[14] N. Gobron and M. Verstraete, ECV T10: Fraction of Absorbed Photosynthetically Active Radiation (FAPAR), Food and Agriculture Organization, United Nations, Rome, Italy, 2009.

[15] GCOS, "G. Systematic observation requirements for satellitebased products for climate. 2011 update supplemetnatl details to the satellite 39 based component og the implementation plan for the global observing system for climate in support of the unfccc (2010 update)," Tech. rep, World Meteorological Organisation (WMO) 7 bis, avenue de la Paix, $\mathrm{CH}-1211,2011$.

[16] B. Xu, T. Park, K. Yan et al., "Analysis of global LAI/FPAR products from VIIRS and MODIS sensors for spatio- temporal consistency and uncertainty from 2012-2016," Forests, vol. 9, no. 2, p. 73, 2018.

[17] J. Clevers, L. Kooistra, and M. M. M. van den Brande, "Using Sentinel-2 data for retrieving LAI and leaf and canopy chlorophyll content of a potato crop," Remote Sensing, vol. 9, no. 5, p. 405, 2017.

[18] L. Korhonen, Hadi, P. Packalen, and M. Rautiainen, "Comparison of Sentinel-2 and Landsat 8 in the estimation of boreal forest canopy cover and leaf area index," Remote Sensing of Environment, vol. 195, pp. 259-274, 2017.

[19] D. Huang, Y. Knyazikhin, W. Wang et al., "Stochastic transport theory for investigating the three-dimensional canopy structure from space measurements," Remote Sensing of Environment, vol. 112, no. 1, pp. 35-50, 2008.

[20] K. Yan, T. Park, G. Yan et al., "Evaluation of MODIS LAI/FPAR product collection 6. Part 1: consistency and improvements," Remote Sensing, vol. 8, no. 5, p. 359, 2016.

[21] P. Jiabin, K. Yan, G. Zhou et al., "Evaluation of the MODIS LAI/FPAR algorithm based on 3D-RTM simulations: a case study of grassland," Remote Sensing, vol. 12, no. 20, article 3391, 2020.

[22] R. B. Myneni and D. L. Williams, "On the relationship between FAPAR and NDVI," Remote Sensing of Environment, vol. 49, no. 3, pp. 200-211, 1994.

[23] Y. Knyazikhin, "MODIS leaf area index (LAI) and fraction of photosynthetically active radiation absorbed by vegetation (FPAR) product (MOD 15) algorithm theoretical basis document," 1999, https://modis.gsfc.nasa.gov/data/atbd/atbd_ mod15.pdf.

[24] J. L. Privette, R. B. Myneni, Y. Knyazikhin et al., "Early spatial and temporal validation of MODIS LAI product in the southern Africa Kalahari," Remote Sensing of Environment, vol. 83, no. 1-2, pp. 232-243, 2002.

[25] W. Yang, B. Tan, D. Huang et al., "MODIS leaf area index products: from validation to algorithm improvement," IEEE Transactions on Geoscience and Remote Sensing, vol. 44, pp. 1885-1898, 2006.

[26] H. Fang, S. Wei, and S. Liang, "Validation of MODIS and CYCLOPES LAI products using global field measurement data," Remote Sensing of Environment, vol. 119, pp. 43-54, 2012.

[27] K. Yan, T. Park, G. Yan et al., "Evaluation of MODIS LAI/FPAR product collection 6. Part 2: validation and intercomparison," Remote Sensing, vol. 8, no. 6, p. 460, 2016.

[28] H. Fang, Y. Zhang, S. Wei et al., "Validation of global moderate resolution leaf area index (LAI) products over croplands in northeastern China," Remote Sensing of Environment, vol. 233, article 111377, 2019.

[29] X. I. A. O. Xiangming, B. Chandrashekhar, W. Audrey, S. Sage, and Y. Chen, "Recovery of Vegetation Canopy after Severe Fire in 2000 at the Black Hills National Forest,South Dakota, USA," Journal of Resources and Ecology, vol. 2, pp. 106-116, 2011.

[30] R. B. Myneni, W. Yang, R. R. Nemani, A. R. Huete, and V. V. Salomonson, "Large seasonal swings in leaf area of Amazon rainforests," Proceedings of the National Academy of Sciences of the United States of America, vol. 104, no. 12, pp. 48204823, 2007.

[31] Q. Mu, F. A. Heinsch, M. Zhao, and S. W. Running, "Development of a global evapotranspiration algorithm based on MODIS and global meteorology data," Remote Sensing of Environment, vol. 111, no. 4, pp. 519-536, 2007. 
[32] H. Fang, S. Liang, and G. Hoogenboom, "Integration of MODIS LAI and vegetation index products with the CSMCERES-maize model for corn yield estimation," International Journal of Remote Sensing, vol. 32, no. 4, pp. 1039-1065, 2011.

[33] K. Yan, T. Park, C. Chen et al., "Generating global products of LAI and FPAR from SNPP-VIIRS data: theoretical background and implementation," IEEE Transactions on Geoscience and Remote Sensing, vol. 56, no. 4, pp. 21192137, 2018.

[34] X. Y. Li, H. G. Huang, N. V. Shabanov, L. Chen, K. Yan, and J. Shi, "Extending the stochastic radiative transfer theory to simulate BRF over forests with heterogeneous distribution of damaged foliage inside of tree crowns," Remote Sensing of Environment, vol. 250, article 112040, 2020.

[35] Y. L. Zeng, J. Li, Q. H. Liu et al., “A Radiative transfer model for patchy landscapes based on stochastic Radiative transfer theory," IEEE Transactions on Geoscience and Remote Sensing, vol. 58, no. 4, pp. 2571-2589, 2020.

[36] Y. L. Zeng, G. Badgley, M. Chen et al., “A radiative transfer model for solar induced fluorescence using spectral invariants theory," Remote Sensing of Environment, vol. 240, article 111678, 2020.

[37] M. Weiss, F. Baret, G. J. Smith, I. Jonckheere, and P. Coppin, "Review of methods for in situ leaf area index (LAI) determination: Part II. Estimation of LAI, errors and sampling," Meteorologie, vol. 121, no. 1-2, pp. 37-53, 2004.

[38] H. Fang, F. Baret, S. Plummer, and G. Schaepman-Strub, “An overview of global leaf area index (LAI): methods, products, validation, and applications," Reviews of Geophysics, vol. 57, no. 3, pp. 739-799, 2019.

[39] G. J. Yan, R. H. Hu, J. H. Luo et al., "Review of indirect optical measurements of leaf area index: recent advances, challenges, and perspectives," Agricultural and Forest Meteorology, vol. 265, pp. 390-411, 2019.

[40] C. Chen, R. Dubin, and M. C. Kim, "Emerging trends and new developments in regenerative medicine: a scientometric update (2000 - 2014)," Expert Opinion on Biological Therapy, vol. 14, no. 9, pp. 1295-1317, 2014.

[41] C. Chen, "Science mapping: a systematic review of the literature," Journal of Data and Information Science, vol. 2, no. 2, pp. 1-40, 2017.

[42] K. Hu, K. Qi, Q. Guan et al., “A Scientometric visualization analysis for night-time light remote sensing research from 1991 to 2016," Remote Sensing, vol. 9, no. 8, p. 802, 2017.

[43] A. Martin-Martin, E. Orduna-Malea, M. Thelwall, and E. Delgado Lopez-Cozar, "Google scholar, web of science, and Scopus: a systematic comparison of citations in $252 \mathrm{sub}-$ ject categories," Journal of Informetrics, vol. 12, no. 4, pp. 1160-1177, 2018.

[44] X. Zou, W. L. Yue, and V. Hai Le, "Visualization and analysis of mapping knowledge domain of road safety studies," Accident Analysis \& Prevention, vol. 118, pp. 131-145, 2018.

[45] X. Cui, X. Guo, Y. Wang et al., "Application of remote sensing to water environmental processes under a changing climate," Journal of Hydrology, vol. 574, pp. 892-902, 2019.

[46] J. Lou, S. J. Tian, S. M. Niu et al., "Coronavirus disease 2019: a bibliometric analysis and review," European Review for Medical and Pharmacological Sciences, vol. 24, no. 6, pp. 34113421, 2020.
[47] N. Donthu, S. Kumar, and D. Pattnaik, "Forty-five years of Journal of Business Research: A bibliometric analysis," Journal of Business Research, vol. 109, pp. 1-14, 2020.

[48] Y. Okubo, Bibliometric indicators and analysis of research systems: methods and examples, OECD, Directorate for Science, Technology and Industry, OECD Science, Technology and Industry Working Papers, 1997.

[49] A. F. J. Van Raan, Advances in Bibliometric Analysis: Research Performance Assessment and Science Mapping, Portland Press Limited, London, 2014.

[50] J. P. Romanelli, J. T. Fujimoto, M. D. Ferreira, and D. H. Milanez, "Assessing ecological restoration as a research topic using bibliometric indicators," Ecological Engineering, vol. 120, pp. 311-320, 2018.

[51] J. Li, M. H. Wang, and Y. S. Ho, "Trends in research on global climate change: a science citation index expanded-based analysis," Global \& Planetary Change, vol. 77, no. 1-2, pp. 13-20, 2011.

[52] J. Liao and Y. Huang, "Global trend in aquatic ecosystem research from 1992 to 2011," Scientometrics, vol. 98, no. 2, pp. 1203-1219, 2014.

[53] J. M. Merigo and J. B. Yang, "A bibliometric analysis of operations research and management science," Omega, vol. 73, pp. 37-48, 2017.

[54] C. M. Chen, "CiteSpace II: detecting and visualizing emerging trends and transient patterns in scientific literature," Journal of the American Society for Information Science and Technology, vol. 57, no. 3, pp. 359-377, 2006.

[55] E. Garfield, "From the science of science to Scientometrics visualizing the history of science with HistCite software," Journal of Informetrics, vol. 3, no. 3, pp. 173-179, 2009.

[56] E. Lazega, S. Wasserman, and K. Faust, "social network Analysis: methods and applications," Revue Franaise De Sociologie, vol. 36, no. 4, pp. 781-783, 1995.

[57] F. Mali, L. Kronegger, P. Doreian, and A. Ferligoj, Dynamic scientific co-authorship networks. In Models of Science Dynamics, Springer, Berlin/Heidelberg, 2012.

[58] C. Chen, “The CiteSpace Manual," 2014, https://leanpub .com/howtousedcitespace.

[59] B. H. Mayhew and R. L. Levinger, "Size and the density of interaction in human aggregates," American Journal of Sociology, vol. 82, no. 1, pp. 86-110, 1976.

[60] M. E. J. Newman, "Modularity and community structure in networks," Proceedings of the National Academy of Sciences, vol. 103, no. 23, pp. 8577-8582, 2006.

[61] N. Shibata, Y. Kajikawa, Y. Takeda, and K. Matsushima, "Detecting emerging research fronts based on topological measures in citation networks of scientific publications," Technovation, vol. 28, no. 11, pp. 758-775, 2008.

[62] C. Chen, F. Ibekwe-SanJuan, and J. Hou, "The structure and dynamics of cocitation clusters: a multiple-perspective cocitation analysis," Journal of the American Society for Information Science and Technology, vol. 61, no. 7, pp. 1386-1409, 2010.

[63] J. Kleinberg, "Bursty and hierarchical structure in streams," Data Mining and Knowledge Discovery, vol. 7, no. 4, pp. 373-397, 2003.

[64] J. E. Hirsch, "An index to quantify an individual's scientific research output," Proceedings of the National Academy of Sciences of the United States of America, vol. 102, no. 46, pp. 16569-16572, 2005. 
[65] M. Schirrmann, A. Hamdorf, A. Giebel, K.-H. Dammer, and A. Garz, "A mobile sensor for leaf area index estimation from canopy light transmittance in wheat crops," Biosystems Engineering, vol. 140, pp. 23-33, 2015.

[66] N. C. Coops, M. A. Wulder, D. C. Duro, T. Han, and S. Berry, "The development of a Canadian dynamic habitat index using multi-temporal satellite estimates of canopy light absorbance," Ecological Indicators, vol. 8, no. 5, pp. 754766, 2008.

[67] B. Szulczewska, R. Giedych, J. Borowski et al., "How much green is needed for a vital neighbourhood? In search for empirical evidence," Land Use Policy, vol. 38, pp. 330-345, 2014.

[68] J. M. Chen, S. C. Thomas, Y. Yin et al., "Enhancing forest carbon sequestration in China: toward an integration of scientific and socio-economic perspectives," Journal of Environmental Management, vol. 85, no. 3, pp. 515-523, 2007.

[69] Z. Zhu, S. Piao, R. B. Myneni et al., "Greening of the earth and its drivers," Nature Climate Change, vol. 6, no. 8, pp. 791$795,2016$.

[70] T. Dunning, "Accurate methods for the statistics of surprise and coincidence," Computational Linguistics, vol. 19, 1993.

[71] D. P. Turner, W. D. Ritts, W. B. Cohen et al., "Scaling gross primary production (GPP) over boreal and deciduous forest landscapes in support of MODIS GPP product validation," Remote Sensing of Environment, vol. 88, no. 3, pp. 256-270, 2003.

[72] R. B. Myneni, R. Ramakrishna, R. R. Nemani, and S. W. Running, "Estimation of global leaf area index and absorbed par using radiative transfer models," IEEE Transactions on Geoscience and Remote Sensing, vol. 35, no. 6, pp. 1380-1393, 1997.

[73] Y. Knyazikhin, J. Martonchik, R. B. Myneni, D. Diner, and S. W. Running, "Synergistic algorithm for estimating vegetation canopy leaf area index and fraction of absorbed photosynthetically active radiation from MODIS and MISR data," Journal of Geophysical Research: Atmospheres, vol. 103, no. D24, pp. 32257-32275, 1998.

[74] Y. Knyazikhin, J. V. Martonchik, D. J. Diner et al., "Estimation of vegetation canopy leaf area index and fraction of absorbed photosynthetically active radiation from atmosphere-corrected MISR data," Journal of Geophysical Research-Atmospheres, vol. 103, no. D24, pp. 32239-32256, 1998.

[75] Y. J. Wang, Y. H. Tian, Y. Zhang et al., "Investigation of product accuracy as a function of input and model uncertainties: case study with SeaWiFS and MODIS LAI/FPAR algorithm," Remote Sensing of Environment, vol. 78, no. 3, pp. 299-313, 2001.

[76] W. B. Cohen, T. K. Maiersperger, Z. Q. Yang et al., "Comparisons of land cover and LAI estimates derived from ETM+ and MODIS for four sites in North America: a quality assessment of 2000/2001 provisional MODIS products," Remote Sensing of Environment, vol. 88, no. 3, pp. 233-255, 2003.

[77] C. O. Justice, J. R. G. Townshend, E. F. Vermote et al., "An overview of MODIS land data processing and product status," Remote Sensing of Environment, vol. 83, no. 1-2, pp. 3$15,2002$.

[78] Y. J. Wang, C. E. Woodcock, W. Buermann et al., "Evaluation of the MODIS LAI algorithm at a coniferous forest site in Fin- land," Remote Sensing of Environment, vol. 91, no. 1, pp. 114127, 2004.

[79] R. Fensholt, I. Sandholt, and M. S. Rasmussen, "Evaluation of MODIS LAI, fAPAR and the relation between FAPAR and NDVI in a semi-arid environment using in situ measurements," Remote Sensing of Environment, vol. 91, no. 3-4, pp. 490-507, 2004.

[80] J. T. Morisette, F. Baret, J. L. Privette et al., "Validation of global moderate-resolution LAI products: a framework proposed within the CEOS land product validation subgroup," IEEE Transactions on Geoscience and Remote Sensing, vol. 44, pp. 1804-1817, 2006.

[81] Wenze Yang, Dong Huang, Bin Tan et al., “Analysis of leaf area index and fraction of PAR absorbed by vegetation products from the terra MODIS sensor: 2000-2005," IEEE Transactions on Geoscience and Remote Sensing, vol. 44, no. 7, pp. 1829-1842, 2006.

[82] J. Pisek and J. M. Chen, "Comparison and validation of MODIS and VEGETATION global LAI products over four BigFoot sites in North America," Remote Sensing of Environment, vol. 109, no. 1, pp. 81-94, 2007.

[83] S. Garrigues, R. Lacaze, F. Baret et al., "Validation and intercomparison of global leaf area index products derived from remote sensing data," Journal of Geophysical Research-Biogeosciences, vol. 113, no. G2, 2008.

[84] F. Baret, O. Hagolle, B. Geiger et al., "LAI, fAPAR and fCover CYCLOPES global products derived from VEGETATION: Part 1: Principles of the algorithm," Remote Sensing of Environment, vol. 110, no. 3, pp. 275-286, 2007.

[85] Z. Xiao, S. Liang, J. Wang et al., "Use of general regression neural networks for generating the GLASS leaf area index product from time-series MODIS surface reflectance," IEEE Transactions on Geoscience and Remote Sensing, vol. 52, no. 1, pp. 209-223, 2014.

[86] Q. $\mathrm{Mu}, \mathrm{M}$. Zhao, and S. W. Running, "Improvements to a MODIS global terrestrial evapotranspiration algorithm," Remote Sensing of Environment, vol. 115, no. 8, pp. 17811800, 2011.

[87] F. Camacho, J. Cernicharo, R. Lacaze, F. Baret, and M. Weiss, "GEOV1: LAI, FAPAR essential climate variables and FCOVER global time series capitalizing over existing products. Part 2: validation and intercomparison with reference products," Remote Sensing of Environment, vol. 137, pp. 310329,2013

[88] Z. Zhu, J. Bi, Y. Pan et al., "Global data sets of vegetation leaf area index (LAI) $3 \mathrm{~g}$ and fraction of photosynthetically active radiation (FPAR) $3 \mathrm{~g}$ derived from global inventory modeling and mapping studies (GIMMS) normalized difference vegetation index (NDVI3g) for the period 1981 to 2011," Remote Sensing, vol. 5, pp. 927-948, 2013.

[89] Z. Xiao, S. Liang, J. Wang, Y. Xiang, X. Zhao, and J. Song, "Long-time-series global land surface satellite leaf area index product derived from MODIS and AVHRR surface reflectance," IEEE Transactions on Geoscience and Remote Sensing, vol. 54, no. 9, pp. 5301-5318, 2016.

[90] G. Salton, A. Wong, and C. S. Yang, "A vector-space model for information retrieval," Communications of the ACM, vol. 18, pp. 13-620, 1975.

[91] I. H. Witten and E. Frank, Data Mining: Practical Machine Learning Tools and Techniques with Java Implementations, Morgan Kaufmann, San Francisco, CA, USA, 1999. 
[92] Y. Liu, J. Xiao, W. Ju et al., "Satellite-derived LAI products exhibit large discrepancies and can lead to substantial uncertainty in simulated carbon and water fluxes," Remote Sensing of Environment, vol. 206, pp. 174-188, 2018.

[93] X. Xie, A. Li, H. Jin et al., "Assessment of five satellite-derived LAI datasets for GPP estimations through ecosystem models," Science of The Total Environment, vol. 690, pp. 1120-1130, 2019.

[94] F. Baret, S. Jacquemoud, G. Guyot, and C. Leprieur, "Modeled analysis of the biophysical nature of spectral shifts and comparison with information content of broad bands," Remote Sensing of Environment, vol. 41, no. 2-3, pp. 133142, 1992.

[95] A. Shneider, "Four stages of a scientific discipline; four types of scientist," Trends in Biochemical Sciences, vol. 34, no. 5, pp. 217-223, 2009.

[96] G. M. Vainikko, "Transfer approach to the mean intensity of radiation in non-continuous clouds," Trudy MGK SSSR, Meteorological Investigations, vol. 21, pp. 28-37, 1973.

[97] G. M. Vainikko, "An equation for the mean intensity of the radiation in broken cloudiness," Trudy MGK SSSR, Meteorological Investigations, vol. 21, pp. 28-37, 1973.

[98] G. A. Titov, "Statistical description of radiation transfer in clouds," Journal of the Atmospheric Sciences, vol. 47, pp. 2438, 2010.

[99] N. V. Shabanov, Y. Knyazikhin, F. Baret, and R. B. Myneni, "Stochastic modeling of radiation regime in discontinuous vegetation canopies," Remote Sensing of Environment, vol. 74, no. 1, pp. 125-144, 2000.

[100] P. Stenberg, M. Mottus, and M. Rautiainen, "Photon recollision probability in modelling the radiation regime of canopies - A review," Remote Sensing of Environment, vol. 183, pp. 98-108, 2016.

[101] D. Huang, Y. Knyazikhin, R. E. Dickinson et al., "Canopy spectral invariants for remote sensing and model applications," Remote Sensing of Environment, vol. 106, no. 1, pp. 106-122, 2007.

[102] A. Cescatti, "Effects of needle clumping in shoots and crowns on the radiative regime of a Norway spruce canopy," Annales des Sciences Forestières, vol. 55, no. 1-2, pp. 89-102, 1998.

[103] O. Panferov, Y. Knyazikhin, R. B. Myneni et al., "The Role of Canopy Structure in the Spectral Variation of Transmission and Absorption of Solar Radiation in Vegetation Canopies," IEEE Transactions on Geoscience \& Remote Sensing, vol. 39, no. 2, pp. 241-253, 2001.

[104] M. Rautiainen and P. Stenberg, "Application of photon recollision probability in coniferous canopy reflectance simulations," Remote Sensing of Environment, vol. 96, no. 1, pp. 98-107, 2005.

[105] P. Lukes, M. Rautiainen, P. Stenberg, and Z. Malenovsky, "Empirical test of the spectral invariants theory using imaging spectroscopy data from a coniferous forest," International Journal of Applied Earth Observation and Geoinformation, vol. 13, no. 4, pp. 668-675, 2011.

[106] Y. Knyazikhin, M. A. Schull, P. Stenberg et al., "Hyperspectral remote sensing of foliar nitrogen content," Proceedings of the National Academy of Sciences of the United States of America, vol. 110, no. 3, pp. E185-E192, 2013.

[107] Y. L. Zeng, G. Badgley, B. Dechant, Y. Ryu, M. Chen, and J. A. Berry, "A practical approach for estimating the escape ratio of near-infrared solar- induced chlorophyll fluorescence,"
Remote Sensing of Environment, vol. 232, article 111209, 2019.

[108] R. E. Murphy, W. L. Barnes, A. I. Lyapustin et al., "Using VIIRS to provide data continuity with MODIS," in IGARSS 2001. Scanning the Present and Resolving the Future. Proceedings. IEEE 2001 International Geoscience and Remote Sensing Symposium (Cat. No.01CH37217), pp. 1212-1214, Sydney, NSW, Australia, 2001.

[109] R. E. Murphy, P. Ardanuy, F. J. Deluccia, J. E. Clement, and C. F. Schueler, "The Visible Infrared Imaging Radiometer Suite," in Earth Science Satellite Remote Sensing, J. J. Qu, W. Gao, M. Kafatos, R. E. Murphy, and V. V. Salomonson, Eds., pp. 199-223, Springer, Berlin, Heidelberg, 2006.

[110] C. Cao, F. J. D. Luccia, X. Xiong, R. Wolfe, and F. Weng, "Early on-orbit performance of the visible infrared imaging radiometer suite onboard the Suomi National PolarOrbiting Partnership (S-NPP) satellite," IEEE Transactions on Geoence and Remote Sensing, vol. 52, pp. 1142-1156, 2013.

[111] S. Jacquemoud, W. Verhoef, F. Baret et al., "PROSPECT + SAIL models: A review of use for vegetation characterization," Remote Sensing of Environment, vol. 113, pp. S56S66, 2009. 